\title{
¿QUÉ ROL Y JUSTIFICACIÓN TIENE EL CONTROL DE IDENTIDAD DE UNA PERSONA EN NUESTRO SISTEMA PROCESAL PENAL CONSIDERANDO EL ACTUAL TEXTO DEL ARTÍCULO 85 DEL CÓDIGO PROCESAL PENAL?*
}

Roberto Rabi González.*.

Introducción; 1. El texto del artículo 85 CPP y su historia; 2. El control de identidad en el sistema procesal penal actualmente vigente: 2.1. Hipótesis de procedencia del control de identidad; 2.2. Limites y restricciones del control de identidad; 3. Casos fundados e indicio: 3.1 "Caso fundado": 3.1.1 Nuestra propuesta; 3.1.2 Jurisprudencia de los Estados Unidos; 3.2 Indicio: 3.2.1 Noción de indicio; 3.2.2 Oportunidad de la apreciación del indicio; 3.2.3 Alcance del indicio; 4. Control de identidad y detención: 4.1 Primera linea argumental: incompatibilidad absoluta entre control de identidad y detención; 4.2 Segunda linea argumental: compatibilidad entre control de identidad y detención; Conclusiones; Bibliografía.

\section{Introducción}

En el presente trabajo pretendemos responder la pregunta sobre ¿Qué rol y justificación tiene el control de identidad de una persona en nuestro sistema procesal penal considerando el actual texto del artículo 85 del Código Procesal Penal'? Se trata de un asunto que nos parece de gran relevancia, toda vez que es un tema no zanjado, en torno al cual los diversos intervinientes en dicho sistema, doctrina y jurisprudencia, evidencian visiones diversas y discrepantes sobre las cuestiones fundamentales de este procedimiento, esto es, qué rol cumple en el sistema, cuál es su finalidad, de qué manera se relaciona con otras medidas restrictivas de la libertad de las personas, como la detención, y en qué situaciones de hecho concretas es procedente.

Además, se trata de un problema de muy actual vigencia por la reciente reforma de la fuente legal del control de identidad, en virtud de la entrada en vigencia de la ley 20.253, publicada en el día 14 de marzo de 2008, en el contexto de la denominada agenda corta antidelincuencia que modificó, entre otras disposiciones relevantes del CPP, el texto del artículo citado, incorporando elementos nuevos y trascendentes para este análisis.

\footnotetext{
* El presente artículo fue publicado previamente en Revista de Derecho de la Universidad Católica de la Santísima Concepción, No $18,2008-2$.

** Abogado, Licenciado en Ciencias Jurídicas y Sociales de la Universidad de Chile y profesor de Derecho Penal y Procesal Penal de la Universidad Autónoma de Chile; email: rrabi@minpublico.cl ${ }^{1}$ En adelante "CPP". 
Rabi - ¿Qué rol y justificación tiene el control de identidad de una persona...

También nos parece interesante el estudio de la institución a que nos referimos por las consecuencias prácticas de gran relevancia que se desprenden de la interpretación que se haga acerca de su procedencia y sobre la manera como se lleva a cabo, lo que, a su vez, puede repercutir en el desarrollo de una investigación, sobre todo de existir un pronunciamiento jurisdiccional sobre la ilegalidad del control de identidad y de actos que fueron consecuencia de éste, como una eventual detención de la persona sometida a control de identidad o la obtención de evidencia en el contexto del mismo. Particular importancia tiene en este sentido la manera como se entiende el sistema de derechos fundamentales, la cual condiciona la interpretación que se haga del artículo 85 CPP y con ello evidentemente los efectos jurídicos y prácticos a los que hemos hecho alusión.

Buena parte de las discrepancias tienen su origen en diversas maneras de entender los objetivos del trabajo policial. Ciertas posiciones que entienden, a nuestro juicio de una manera equivocada, la defensa de los derechos fundamentales, desconocen la función social del trabajo de las policías y, sobre todo, la realidad fáctica del entorno en que tienen lugar los procedimientos a que nos vamos a referir, en términos tales que terminan debilitando la institución al punto de que, si tomamos en serio esos argumentos, el control de identidad carecería de toda utilidad práctica. Intentaremos fundamentar una visión realista revisando situaciones concretas e identificando en cada caso estándares que nos llevan a concluir que el control de identidad es una herramienta de prevención y persecución penal, sin por ello ser un escollo para el respeto de las libertades fundamentales entendidas de una manera adecuada, esto es, como garantías de rango constitucional imprescindibles para el sano funcionamiento de una sociedad, pero que no por eso son absolutas, ni es improcedente que se les limite o restrinja, con arreglo a derecho, teniendo a su vez a la vista para ello la protección de otros valores, también fundamentales.

Intentaremos contestar las interrogantes que hemos planteado anteriormente considerando los principios que orientan la lógica de la reforma procesal penal y en especial la constante tensión entre la búsqueda de la eficiencia en la persecución penal, por una parte, y el pleno respeto de las garantías fundamentales de las personas, por otro. El tipo de respuestas que se puedan formular dependerá de si se acepta o no tal tensión fundamental y el rol primordial que ésta cumple. Compartimos el planteamiento de los profesores Duce y Riego: "frente a tal situación de conflicto hay quienes intentan demostrar que la contradicción es sólo aparente, ya que sería posible entender que ambos objetivos son equivalentes o al menos complementarios, No nos parece que este esfuerzo sea convincente ya que tiende a ocultar una tensión efectivamente existente en el proceso, que acarrea consecuencias muy directas para las personas y que, por lo mismo, siempre debe tenerse presente para su diseño y para comprender su funcionamiento". ${ }^{2}$

2 Duce, Mauricio y Riego, Cristián: Proceso Penal, Editorial Jurídica de Chile, Santiago, 2007, p. 29. 
Comenzaremos revisando el origen de la institución y sus distintas modificaciones (Capitulo 1), con el propósito de identificar los objetivos que se tuvieron a la vista al instaurarla y la manera como se ha entendido, considerando las pretensiones específicas detrás de cada reforma. Luego nos centraremos en el texto actualmente vigente del artículo 85 CPP (Capitulo 2) y su rol en el sistema. A continuación nos detendremos en los fundamentos de procedencia en la legislación actualmente vigente (Capitulo 3), en particular analizando las nociones de "casos fundados" e "indicios" vinculando tal análisis a la realidad y objetivos del trabajo policial, recurriendo en tal tarea, además de la legislación vigente, doctrina y jurisprudencia nacional, a ciertos fallos relevantes de jurisprudencia comparada, en particular de los Estados Unidos, para luego examinar la relación entre el control de identidad y la detención (Capitulo 4). Finalmente, expondremos las conclusiones de nuestro trabajo.

\section{El texto del artículo 85 CPP y su historia}

Una breve explicación de la historia del actual texto del artículo 85 CPP es útil para comprender la función que cumple en el sistema procesal penal chileno hoy. Tal exposición no puede sino comenzar con el origen de tal disposición, que recoge en parte finalidades que durante buena parte de la vigencia del Código de Procedimiento Penal se atribuyeron a la denominada detención por sospecha y, por lo mismo, suele vincularse la instauración del control de identidad a la supresión definitiva de aquella polémica figura.

El artículo 260 del Código de Procedimiento Penal disponía:

"Los agentes de policía están obligados a detener (...)

$3^{\circ} \mathrm{Al}$ que anduviere con disfraz o de otra manera que dificulte o disimule su verdadera identidad y rehúse darla a conocer. ${ }^{3}$

$4^{\circ} \mathrm{Al}$ que se encontrare a deshora $\mathrm{o}$ en lugares $\mathrm{o}$ en circunstancias que presten motivo fundado para atribuirle malos designios si las explicaciones que diere de su conducta no desvanecieren las sospechas".

Así, en cuanto a su origen, en términos generales no podemos sino concordar con Adolfo Cisternas Pino, en cuanto a que el control de identidad fue y ha sido entendido como “...el 'sucesor legal' del procedimiento policial denominado 'detención por sospecha', que era una forma de privación de libertad por tiempo breve, y con fines de prevención especial que llevaban a cabo las policías". ${ }^{4}$ La mera apreciación de este tránsito, que se ha convertido

\footnotetext{
3 Antes de la ley 18.857, de 6 de diciembre de 1989, el numeral citado hacía referencia "al que ande disfrazado y rehúse darse a conocer".

${ }^{4}$ Cisternas Pino, Adolfo: La detención por flagrancia, Librotecnia, Santiago, 2005, p. 117.
} 
Rabi - ¿Qué rol y justificación tiene el control de identidad de una persona...

en un lugar común en nuestro entorno, arroja claridad respecto a las necesidades que se tuvieron a la vista en la gestación de la normativa del control de identidad: existe unanimidad en nuestra doctrina en afirmar que la detención por sospecha tuvo una aplicación arbitraria y contraria a garantías fundamentales como el derecho a la libertad ambulatoria, la igualdad ante la ley y otras de similar relevancia, sustentando una "lógica de otorgar facultades a la policía para ejercer funciones de control, que (tenían) un contenido punitivo, al margen de los supuestos formales del sistema de justicia criminal". ${ }^{5}$

Ya en 1993 un grupo de parlamentarios ${ }^{6}$ presentó un proyecto que logró el respaldo del Ejecutivo, que buscaba eliminar los números $3^{\circ}$ y $4^{\circ}$ del artículo 260 del Código de Procedimiento Penal, buscando "compatibilizar los derechos de las personas con los procedimientos penales y de detención". ${ }^{7} \mathrm{Tal}$ iniciativa condujo a la ley 19.567, de 1 de julio de 1998, que además de eliminar la denominada "detención por sospecha" incorporó la formulación original del control de identidad en el artículo 260 bis del citado cuerpo legal ${ }^{8}$, al suprimir la controvertida disposición, se consideró necesario dotar a las policías de un instrumento básico de carácter investigativo y sobre todo de prevención y persecución criminal que compensara de alguna forma la supresión de la detención por sospecha.

Tal constatación, que si bien es cierto no es suficiente por sí sola para delimitar con precisión la naturaleza y fines del control de identidad y, consecuencialmente, las causales que la justifican, nos permite formarnos una idea bastante clara de por qué los legisladores llegaron a instaurarlo, primero en el Código de Procedimiento Penal, y luego en el Código Procesal Penal.

La redacción original del artículo 260 bis del Código de Procedimiento Penal es bastante parecida a la manera como fue recogida en el CPP. En la discusión parlamentaria generada a propósito de la incorporación del control

\footnotetext{
${ }^{5}$ González, Felipe y Riego, Cristián: "Las Garantías de la Detención en Chile" en Proceso Penal y Derechos Fundamentales, Corporación nacional de Reparación y Reconciliación, Santiago, 1994, p. 208.

${ }^{6}$ Los diputados Mario Devaud, Juan Pablo Letelier, Carlos Montes, Adriana Muñoz y Andrés Palma.

${ }^{7}$ González, Felipe y Riego, Cristián: “Las Garantías...”, (nota 5), p. 206.

${ }^{8}$ El texto del artículo 260 bis del Código de Procedimiento Penal es el siguiente: "La policía podrá solicitar la identificación de cualquier persona, en casos fundados, tales como la existencia de un indicio de que ella ha cometido o intentado cometer un crimen o simple delito, o de que se dispone a cometerlo, o de que puede suministrar informaciones útiles para la indagación de un crimen o simple delito. La identificación se realizará en el lugar en que la persona se encuentre, debiendo dársele todas las facilidades posibles para acreditarla, lo que podrá hacer por cualquier medio. En caso de negativa de una persona a acreditar su identidad o si, habiendo recibido las facilidades del caso no le ha sido posible acreditarla, la policía la conducirá a la unidad policial más cercana, para dar cumplimiento a lo dispuesto por el artículo 266. El ejercicio abusivo de esta facultad o la negativa a dar facilidades para permitir la identificación serán sancionados disciplinariamente en los términos del inciso final del artículo 293".
} 
de identidad en el Código Procesal Penal, "se discutió la forma más adecuada de buscar un equilibrio entre las necesidades de conservación de la seguridad pública y el respeto de los derechos de las personas en el contexto del nuevo Código", lo que demuestra que desde el principio el legislador asumió la ya difundida doctrina sobre los derechos fundamentales, según la cual éstos no tienen un alcance absoluto y, particularmente en el ámbito del Derecho Procesal Penal, deben entenderse en el contexto de un sistema para el cual también es valiosa la persecución criminal, y la adecuada aplicación de las normas que lo integran requerirá de los operadores jurídicos ponderar razonablemente los valores en tensión en cada situación concreta.

Así, la primera formulación del control de identidad ${ }^{10}$ en el CPP, como señalábamos bastante similar a la de su antecedente inmediato, permitía a los agentes de policía solicitar la identificación de cualquier persona en casos fundados, señalando algunos ejemplos de lo que debía entenderse por tales, exigiendo a los funcionarios en cuestión proporcionar todas las facilidades necesarias a la persona sujeta a control, permitiendo el traslado de ésta a la unidad policial más cercana de no haberse conseguido la identificación de la misma y estableciendo un plazo de cuatro horas para el procedimiento, al término del cual la persona debía ser puesta en libertad.

Tal procedimiento, junto con una considerable porción de las instituciones de la entonces reciente reforma del sistema procesal penal, estuvo sometido a una metódica revisión, y en tal contexto se creó la Comisión de

\footnotetext{
${ }^{9}$ Romero Muza, Rubén: Control de Identidad y Detención, Segunda Edición, Librotecnia, Santiago, 2007, p. 39.

${ }^{10}$ La primera redacción del artículo 85 del CPP fue la siguiente:

"Artículo 85. Control de Identidad. Los funcionarios policiales señalados en el artículo 83 podrán, además, sin orden previa de los fiscales solicitar la identificación de cualquier persona en casos fundados, tales como la existencia de un indicio de que ella hubiere cometido o intentado cometer un crimen o simple delito, de que se dispusiere a cometerlo, o de que pudiere suministrar informaciones útiles para la indagación de un crimen o simple delito. La identificación se realizará en el lugar en que la persona se encontrare, por medio de documentos de identificación expedidos por la autoridad pública, como cédula de identidad, licencia de conducir o pasaporte. El funcionario policial deberá otorgar a la persona facilidades para encontrar y exhibir estos instrumentos.

En caso de negativa de una persona a acreditar su identidad, o si habiendo recibido las facilidades del caso no le fuere posible hacerlo, la policía la conducirá a la unidad policial más cercana para fines de identificación. Si no le hubiere sido posible acreditar su identidad, se le darán en ese lugar facilidades para procurar una identificación satisfactoria por otros medios distintos de los ya mencionados. Si esto último no resultare posible, se ofrecerá a la persona ponerla en libertad de inmediato si autorizare por escrito que se le tomen huellas digitales, las que sólo podrán ser utilizadas para fines de identificación.

La facultad policial de requerir la identificación de una persona deberá ejercerse de la forma más expedita posible. En caso alguno el conjunto de procedimientos detallados en los incisos anteriores podrá extenderse por un plazo mayor de cuatro horas transcurridas las cuales será puesta en libertad.
} 
Rabi - ¿Qué rol y justificación tiene el control de identidad de una persona...

Evaluación de la Implementación de la Reforma Procesal Penal, establecida por el Ministro de Justicia el año 2001, cuando la normativa del nuevo código sólo se encontraba vigente en algunas regiones del país, suscitándose problemas prácticos de aplicación de varias de las nuevas instituciones, en un entorno en que la percepción de los intervinientes y opinión pública consideraron la nueva legislación demasiado garantista y restrictiva de las facultades del ente persecutor y sus auxiliares. Tal comisión sostuvo que "el nuevo sistema de controles que la reforma representa se ha constituido en un sistema bastante eficaz sobre la legalidad de las actuaciones policiales especialmente por la intervención del juez y del defensor en las audiencias iniciales. Esta constatación constituye un logro de la reforma que debe ser resaltado. No obstante, la misma estrictez de los controles ha generado problemas operativos que pensamos deben ser solucionados para evitar que el control sobre la actividad policial sea percibido como un obstáculo al eficaz desarrollo del mismo". "En consecuencia, la comisión propuso una serie de modificaciones al texto del artículo $85 \mathrm{CPP}$, buena parte de las cuales fueron recogidas por la primera modificación del artículo en cuestión.

Considerando gran parte de las inquietudes propuestas por la comisión citada, la ley $\mathrm{N}^{\circ} 19.789$ de 30 de enero de 2002 modificó entre otras disposiciones, el artículo 85 CPP, agregando la voz "falta" a las de "crimen o simple delito" que emplea al describir los indicios a que hace referencia, amplió la duración de los procedimientos constitutivos del control de identidad, de cuatro a seis horas, y facultó a los funcionarios policiales para registrar las vestimentas, equipaje o vehículo de las personas cuya identidad se controla. Todo lo anterior con la intención de ampliar las facultades de las policías, que se habían visto bastante disminuidas con las interpretaciones en general restrictivas sostenidas por la doctrina y jurisprudencia de la época.

Además, la modificación precisó que el abuso del funcionario policial a cargo del procedimiento puede ser constitutivo del delito de "abusos contra particulares" previsto y sancionado en el artículo 255 del Código Penal. ${ }^{12} \mathrm{Si}$

\footnotetext{
11 Informe Comisión de Evaluación de la Reforma Procesal, Octubre 2001, p. 19. Esta comisión, establecida por el Ministro de Justicia, estuvo conformada por Rafael Blanco, asesor del Ministro de Justicia; Cristián Riego, investigador de la Universidad Diego Portales; Carlos Valdivieso, Gerente de Fundación Paz Ciudadana, y Juan Enrique Vargas, Director Ejecutivo del Centro de Estudios de Justicia de las Américas y tuvo por finalidad evaluar el funcionamiento de la reforma procesal penal a la fecha y proponer las modificaciones que se estimaran pertinentes. Para tales efectos, la Comisión se desplazó a las dos regiones donde se había puesto en marcha la reforma procesal penal, sosteniendo en ellas sendas reuniones con jueces de Garantía; altos representantes de las Fiscalías Regionales del Ministerio Público; oficiales y personal de Carabineros de Chile y Defensores Públicos. La Comisión también se entrevistó con el Fiscal Nacional Sr. Guillermo Piedrabuena y con el Defensor Público Nacional, Sr. Alex Carocca. Adicionalmente, revisó diversos materiales y antecedentes, tales como estadísticas del funcionamiento del sistema, encuestas de percepción pública e información relativa a los recursos invertidos en la reforma.

12 “Art 255 El empleado público que, desempeñando un acto de servicio, cometiere cualquier vejación injusta contra las personas o usare de apremios ilegítimos o innecesarios para el
} 
bien es cierto que tal mención no es del todo necesaria, porque dicha conducta será o no típica con independencia de la referencia incorporada al artículo 85 CPP si es constitutiva de un efectivo "apremio ilegítimo" o "vejación injusta", tal referencia tiende a reforzar la idea de responsabilidad por los actos de la policía en el ejercicio de sus funciones.

Posteriormente, el debate público generado por la dudosa aplicación de varias de las nuevas instituciones, entre ellas el control de identidad, motivó la creación de otra comisión, que nuevamente se preocupó de las dificultades experimentadas por las policías en el desarrollo de su trabajo orientado a la prevención y persecución penal, planteando de nuevo la necesidad, además de una capacitación orientada al trabajo en el nuevo sistema, de fortalecer y ampliar sus atribuciones. ${ }^{13}$ Tales reflexiones fundamentaron buena parte del contenido de la ley 19.942 de 15 de abril de 2004, la cual, coherente con esta lógica, amplió el alcance del control de identidad, concretamente remplazando la voz "podrán" por el vocablo "deberán" al referirse a la labor de los policías de cara a éste, instaurando la obligación de controlar la identidad, de los agentes policiales en los "casos fundados" a los que se refiere, reforzando la idea de la utilidad social que el legislador vislumbra en la adecuada aplicación de dicho procedimiento. Agregó además la figura de ocultación de identidad al catálogo de faltas del Código Penal, en los términos que actualmente se encuentra consagrada en el artículo $496 \mathrm{~N}^{\circ} 5$ del Código de Castigo. ${ }^{14}$

Finalmente, el día 14 de marzo de 2008 se publicó la ley 20.253 en el contexto de la denominada agenda legislativa "antidelincuencia", destinada a "reforzar las atribuciones preventivas de las policías y enfrentar el creciente temor subjetivo de la ciudadanía ante el actuar de la delincuencia, reprimiendo

desempeño del servicio respectivo, será castigado con las penas de suspensión del empleo en cualquiera de sus grados y multa de once a veinte unidades tributarias mensuales".

${ }^{13}$ Documento de la Comisión Nombrada para Revisar y Evaluar la Marcha y Funcionamiento del Nuevo Sistema de Enjuiciamiento Criminal. Diciembre de 2003. Esta comisión de expertos fue concebida como una instancia de revisión y evaluación sobre la marcha y funcionamiento del sistema de enjuiciamiento criminal generada en el contexto del debate legislativo surgido con ocasión de la propuesta del Ejecutivo para aplazar la entrada en vigencia de la reforma procesal penal en la Región Metropolitana.

Para estos efectos, el ministro de Justicia de la época, don Luis Bates, convocó a integrar la comisión a don Andrés Baytelman, académico de la Universidad Diego Portales; don Rafael Blanco, académico de la Universidad Alberto Hurtado; don Jorge Bofill, académico de la Universidad de Chile; don Axel Buchheister, director del Programa Legislativo del Instituto Libertad y Desarrollo; don Carlos Frontaura, académico de la Pontificia Universidad Católica de Chile; don Orlando Poblete, decano de la Facultad de Derecho de la Universidad de los Andes; don Cristián Riego, académico de la Universidad Diego Portales; don Raúl Tavolari, académico de la Universidad de Chile; don Gonzalo Vargas, Gerente de la Fundación Paz Ciudadana; y don Juan Enrique Vargas, director ejecutivo del Centro de Estudios de Justicia de las Américas.

14 "Art. $496 \mathrm{~N}^{\circ} 5 \mathrm{El}$ que ocultare su verdadero nombre y apellido a la autoridad o a persona que tenga derecho para exigir que los manifieste, o se negare a manifestarlos o diere domicilio falso". 
Rabi - ¿Qué rol y justificación tiene el control de identidad de una persona...

con mayor energía el delito disminuyendo la sensación de temor". ${ }^{15} \mathrm{La}$ normativa aludida, junto con modificar una serie de disposiciones de gran relevancia en el Código Penal, Procesal Penal y Ley Orgánica Constitucional del Ministerio Público, reformó sustancialmente el texto del artículo 85 del CPP. "Esta materia fue una de las más debatidas (...) y formó parte de las ideas matrices del proyecto presentadas en el Mensaje del Ejecutivo". ${ }^{16}$ En definitiva la ley establece el siguiente texto del artículo en cuestión:

Artículo 85.- Control de identidad. Los funcionarios policiales señalados en el artículo 83 deberán, además, sin orden previa de los fiscales, solicitar la identificación de cualquier persona en los casos fundados, en que, según las circunstancias, estimaren que existen indicios de que ella hubiere cometido o intentado cometer un crimen, simple delito o falta; de que se dispusiere a cometerlo; de que pudiere suministrar informaciones útiles para la indagación de un crimen, simple delito o falta; o en el caso de la persona que se encapuche o emboce para ocultar, dificultar o disimular su identidad. La identificación se realizará en el lugar en que la persona se encontrare, por medio de documentos de identificación expedidos por la autoridad pública, como cédula de identidad, licencia de conducir o pasaporte. El funcionario policial deberá otorgar a la persona facilidades para encontrar y exhibir estos instrumentos.

Durante este procedimiento, sin necesidad de nuevos indicios, la policía podrá proceder al registro de las vestimentas, equipaje o vehículo de la persona cuya identidad se controla, y cotejar la existencia de las órdenes de detención que pudieren afectarle. La policía procederá a la detención, sin necesidad de orden judicial y en conformidad a lo dispuesto en el artículo 129, de quienes se sorprenda, a propósito del registro, en alguna de las hipótesis del artículo 130, así como de quienes al momento del cotejo registren orden de detención pendiente.

En caso de negativa de una persona a acreditar su identidad, o si habiendo recibido las facilidades del caso no le fuere posible hacerlo, la policía la conducirá a la unidad policial más cercana para fines de identificación. En dicha unidad se le darán facilidades para procurar una identificación satisfactoria por otros medios distintos de los ya mencionados, dejándola en libertad en caso de obtenerse dicho resultado, previo cotejo de la existencia de órdenes de detención que pudieren afectarle. Si no

\footnotetext{
15 Piedrabuena Richard, Guillermo: Ley 20.253 Agenda Corta Antidelincuencia, Legis, Santiago, 2008, p. 15.

${ }^{16}$ Ibid., p. 90.
} 
resultare posible acreditar su identidad, se le tomarán huellas digitales, las que sólo podrán ser usadas para fines de identificación y, cumplido dicho propósito, serán destruidas.

El conjunto de procedimientos detallados en los incisos precedentes no deberá extenderse por un plazo superior a ocho horas, transcurridas las cuales la persona que ha estado sujeta a ellos deberá ser puesta en libertad, salvo que existan indicios de que ha ocultado su verdadera identidad o ha proporcionado una falsa, caso en el cual se estará a lo dispuesto en el inciso siguiente.

Si la persona se niega a acreditar su identidad o se encuentra en la situación indicada en el inciso anterior, se procederá a su detención como autora de la falta prevista y sancionada en el $\mathrm{N}^{\circ}$ 5 del artículo 496 del Código Penal. El agente policial deberá informar, de inmediato, de la detención al fiscal, quien podrá dejarla sin efecto u ordenar que el detenido sea conducido ante el juez dentro de un plazo máximo de veinticuatro horas, contado desde que la detención se hubiere practicado. Si el fiscal nada manifestare, la policía deberá presentar al detenido ante la autoridad judicial en el plazo indicado.

Los procedimientos dirigidos a obtener la identidad de una persona en conformidad a los incisos precedentes, deberán realizarse en la forma más expedita posible, y el abuso en su ejercicio podrá ser constitutivo del delito previsto y sancionado en el artículo 255 del Código Penal.

Esta última reforma del texto del artículo 85 del CPP, en primer lugar, modifica la redacción del fundamento de procedencia del control de identidad, por las más confusas expresiones: "en los casos fundados, en que, según las circunstancias, estimaren que existen indicios...". Volveremos sobre tal idea con mayor detalle. Por otra parte, agrega una situación específica en que es procedente el control de identidad, cual es el caso de "la persona que se encapuche o emboce para ocultar, dificultar o disimular su identidad". Además, faculta expresamente a la policía a revisar en los registros respectivos, en particular de las propias policías, Ministerio Público y los tribunales de justicia, si la persona cuya identidad se controla mantiene alguna orden de detención pendiente. La reforma amplía nuevamente la duración máxima de los procedimientos propios del control de identidad, de seis a ocho horas. Finalmente, contiene una referencia concreta a la eventual relación que puede existir entre el procedimiento que la disposición regula y la detención de la persona cuya identidad se controla. 
Rabi - ¿Qué rol y justificación tiene el control de identidad de una persona...

Para efectos de dar respuesta a las interrogantes que planteamos al principio de este trabajo, destacamos de la evolución legislativa que hemos revisado los aspectos que nos parecen más relevantes:

a. Se ha creado una institución conceptualmente independiente de la detención, de menor intensidad en la afectación de derechos, pero que, como veremos más adelante, puede conectarse lógica y jurídicamente con la misma, si en el contexto de los procedimientos específicos del control de identidad el imputado comete algún delito o falta que amerita su detención, también si se verifica la existencia de alguna orden de detención pendiente, o en el evento que la policía constate que concurre alguna de las hipótesis de flagrancia descritas en el artículo 130 CPP.

b. Se ha ido ampliando sucesivamente el alcance de las hipótesis ilustrativas de lo que es un caso fundado que justifica la procedencia del control de identidad. Con todo, como expondremos con mayor detalle, la técnica legislativa empleada para este fin nos parece defectuosa, en particular tras la ley 20.253, toda vez que parece hacer referencia a un conjunto cerrado de hipótesis fácticas, en circunstancias que la norma no puede sino referir un concepto amplio que se debe concretar en cada caso mediante análisis de la situación de hecho específica que se enfrente.

c. Se ha ampliado el plazo consecutivamente de cuatro a seis y finalmente a ocho horas la de duración máxima del procedimiento (innovación muy debatida, especialmente en el contexto de la discusión de la ley 20.253, en la cual el aumento fue aprobado por mayoría de votos) y también las facultades que se otorgan a la policía en el contexto del mismo, en particular, registro de vestimentas, de vehículo, traslado a la unidad policial, consulta de órdenes de detención, etc.

d. Se han creado y precisado sanciones tanto para los agentes policiales que se excedan en el ejercicio de sus atribuciones como para quienes oculten su identidad, lo que da cuenta de la idea de reforzar la plena vigencia de la lógica consagrada en esta norma.

A nuestro juicio la redacción previa al texto actualmente vigente era más acertada en cuanto parecía claro que el control de identidad era procedente siempre que concurriera un "caso fundado" y los ejemplos sólo buscaban ilustrar la noción central, describiendo situaciones de hecho que para el legislador eran constitutivas de aquella. Al reemplazarse la redacción anterior por "los casos fundados, en que, según las circunstancias (...)", el texto pierde claridad, toda vez que desde una perspectiva estrictamente lógico-gramatical, 
parece pretender referirse a la totalidad de las circunstancias que son constitutivas de un "caso fundado".

Será tarea de los intervinientes en el sistema procesal penal chileno determinar el alcance específico de los términos según las circunstancias, y básicamente la distinción entre las que forman parte del hecho específico que constituye el caso fundado que la ley detalla y las que a juicio del legislador deben ser relevantes para la apreciación del mismo. Ello sólo es posible aplicando los principios y valores básicos del sistema y teniendo a la vista la finalidad del control de identidad, como institución generada con objetivos prácticos concretos.

La incorporación de la hipótesis de procedencia en "el caso de la persona que se encapuche o emboce para ocultar, dificultar o disimular su identidad..." fue cuestionada en el ámbito del debate parlamentario de la agenda corta antidelincuencia. Así, "la diputada Soto expresó el rechazo (a la indicación citada) porque las personas jóvenes se encapuchaban al salir a las calles, por razones inocuas como por ej. climáticas". ${ }^{17}$ Nos parece razonable tal planteamiento, es más, difícil resulta desconocer que el empleo de vestimentas abrigadas que ocultan buena parte del rostro no es sólo propia de las personas jóvenes, como plantea la diputada, pero lo que nos parece crucial es que la mención es del todo innecesaria, toda vez que una interpretación razonable del texto anteriormente vigente cubría tal situación de hecho, en los casos en que era necesario para fines relevantes de la persecución penal.

Lo que resulta más complejo es que la modificación en este último punto sólo se presta para generar confusión en la medida que parece ser la culminación de una enumeración cerrada de circunstancias de hecho que motivan un control de identidad, lo que consideramos incompatible con la función sistemática de este procedimiento y en particular con la necesidad de dotarlo de un sentido práctico.

Sin embargo afirmamos que la única manera de resguardar la armonía del sistema es sostener aún la lógica que defenderemos más adelante interpretando de manera sistemática el nuevo texto del artículo $85 \mathrm{CPP}$, sin caer en un fundamentalismo exegético sustentado en el mero tenor literal de la disposición citada, que impide dotar al control de identidad de un sentido práctico y de utilidad para los fines que fue ideado, y que como hemos visto, a través de reiteradas modificaciones, basadas en ideas político-criminales claras, el legislador ha pretendido una y otra vez enfatizar, encontrando fuerte resistencia en los operadores jurídicos.

${ }^{17}$ Ibid., p. 94. 
Rabi - ¿Qué rol y justificación tiene el control de identidad de una persona...

\section{El control de identidad en el sistema procesal penal actualmente vigente}

Habitualmente, en la práctica de los actores relevantes en el sistema procesal penal chileno, éstos han entendido que los funcionarios policiales están facultados para exigirle a una persona que se identifique en los términos previstos en el artículo 85 del CPP, únicamente si han constatado la existencia de un indicio de que ella hubiere cometido o intentado cometer un crimen, simple delito o falta; que se dispusiere a cometerlo o de que pudiere suministrar información de relevancia investigativa, desconociendo que tal indicio es expuesto, como un ejemplo explicativo de lo que es un caso fundado para proceder al control de identidad.

Por otra parte se ha discutido intensamente si el control de identidad permite la realización de otras diligencias propias de la investigación en el contexto del mismo, y de qué manera se justificaría, o no, una detención por flagrancia conexa y "si este tipo de flagrancia 'sobreviniente' construida sobre actividades realizadas durante el control de identidad, se encuentra autorizada por la ley, y si la prueba recabada en ella funda válidamente no sólo la detención, sino la actuación investigativa posterior". ${ }^{18}$

Precisamente, estas dos cuestiones: (1) la determinación de las hipótesis de procedencia del control de identidad y (2) los límites del procedimiento en sí, son los temas que nos parecen más relevantes para centrar nuestro estudio.

\subsection{Hipótesis de procedencia del control de identidad}

Afirmamos que el control de identidad en nuestro sistema es un procedimiento que está orientado a que los agentes de la policía exijan la identificación de una persona, sólo en cuanto tal actividad es un mecanismo orientado a materializar fines propios de la investigación y persecución penal, con amplio alcance. Esto es, identificar partícipes en hechos punibles, determinar su participación específica en los mismos, vincularlos a la investigación mediante medidas restrictivas o privativas de libertad, conseguir evidencia e incluso obtener información de testigos o terceros sin vinculación personal a hecho delictual alguno y, en suma, poder desarrollar, a través de los procedimientos específicos que el control de identidad supone (registro de vestimentas, de vehículo, consulta de órdenes de detención, etc.) estrategias de persecución penal de alcance general o especial (lugares o sectores específicos, tipos de delitos, etc.).

La historia de la norma expuesta precedentemente refuerza tal idea, toda vez que, en primer lugar, identificar a una persona no es, ni tiene sentido

\footnotetext{
${ }^{18}$ Romero Muza, Rubén: Control de identidad... (nota 9), p. 85.
} 
que sea, un propósito en sí mismo, sólo resulta razonable exigirle que se identifique, en el marco del rol general que les corresponde a las policías, en particular desarrollando su función preventiva, como también en el papel de auxiliar al Ministerio Público en tareas de investigación y persecución penal, consagrado en el artículo $79 \mathrm{CPP}$.

Así, por ejemplo, en la legislación peruana, el control de identidad se encuentra consagrado en términos claros que no dejan lugar a dudas sobre la función sistemática que la institución cumple: "sin necesidad de orden del Fiscal o del Juez (el agente de policía) podrá requerir la identificación de cualquier persona y realizar las comprobaciones pertinentes en la vía pública o en el lugar donde se hubiere hecho el requerimiento, cuando considere que resulta ser necesario para prevenir un delito u obtener información útil para la averiguación de un hecho punible". ${ }^{19}$ Tal técnica legislativa nos parece acertada toda vez que identifica de manera precisa los motivos de fondo que justifican el control de identidad, sin enredarse en particularidades que deberían ser resueltas en cada caso concreto por los tribunales de justicia.

En el CPP chileno, la referencia a la justificación de fondo está sólo insinuada. Así, los "casos fundados" que justifican la procedencia del control de identidad serán tales (fundados) en la medida que les permitan a las policías materializar dichos objetivos. Ello debió entenderse así desde la redacción original del artículo $85 \mathrm{CPP}$ y también hoy nos parece la manera correcta de interpretar el precepto en cuestión. El Fiscal Nacional del Ministerio Público, en el Oficio 138 de 14 de abril de 2004, que complementa el instructivo vigente a tal fecha sobre control de identidad enfatiza "...el Art. 85 señala dos casos fundados en que se permite a la policía solicitar la identificación de una persona, lo cual no excluye que existan otras situaciones en que pudiera la policía proceder de esta manera". ${ }^{20}$ También en la doctrina tal idea se ha planteado de manera más restrictiva, así se ha postulado que "...el estándar que fija el legislador es del "caso fundado", y a modo ejemplar, mediante las expresiones "tales como", señala que este caso fundado se puede expresar en un indicio con los caracteres que se señalan en la norma. De este modo puede sostenerse que se trata de un estándar alto, en el sentido de que el "caso" debe contar con un fundamento o razón, más allá de la mera intuición abstracta del funcionario". ${ }^{21}$

El legislador ha ido ampliando las hipótesis que ilustran lo que es un "caso fundado", incorporando a la noción genérica ejemplos concretos que sólo se justifican en requerimientos ya mencionados de prevención, persecución e investigación de hechos delictuales. Sin embargo, particularmente con la última reforma al texto del artículo $85 \mathrm{CPP}$, que elimina la expresiones "tales como" y consagra una enumeración más extensa de

\footnotetext{
19 Art. 205 Código Procesal Penal de Perú, (Decreto Legislativo 957).

20 OFICIO FN No 138/2004, p. 1.

${ }^{21}$ Romero Muza, Rubén: Control de identidad... (nota 9), p. 73.
} 
Rabi - ¿Qué rol y justificación tiene el control de identidad de una persona...

situaciones que justifican la realización den un control de identidad, cobra fuerza la idea superficial a que aludimos, esto es, entender que sólo las situaciones descritas expresamente son las que permiten que tenga lugar el control de identidad.

\subsection{Límites y restricciones del control de identidad}

Afirmamos, además, que pese a tratarse de un procedimiento independiente, tanto lógica como jurídicamente, de la detención, no existe incompatibilidad entre tal independencia y la posibilidad de que en el contexto del control de identidad se pueda constatar una situación de flagrancia, e incluso ser tal constatación resultado del ejercicio de facultades de las policías, como las de registro, que son propias del control de identidad. Más aun, la policía puede sospechar una situación de flagrancia, en términos tales que en principio, únicamente dispone de ciertos elementos de juicio insuficientes para proceder de acuerdo con el artículo 130 del CPP, pero suficientes para satisfacer las exigencias del control de identidad, y recabar en el marco del control de identidad de la información necesaria para proceder a la detención. Ello evidencia que el control de identidad posee fines derechamente investigativos.

Las sucesivas ampliaciones del término para llevar a cabo los procedimientos propios del control de identidad también son indicadores de que el legislador ha perseguido maximizar el potencial investigativo de las policías, orientado a esclarecer los ilícitos, determinar los partícipes en los mismos y hacer efectiva su responsabilidad penal por aquellos.

Todo lo anterior:

i. Importa la necesidad de ponderar según adecuados estándares la relación entre la intervención policial y el sistema de derechos fundamentales de las personas, puesto que es universalmente reconocido que "la libertad personal no es un derecho fundamental absoluto sino que puede ser objeto de determinadas restricciones. En consecuencia puede ser restringido en determinados supuestos establecidos en las normas internacionales sobre derechos humanos y en la Constitución" 22 y tal restricción podrá ser de una intensidad distinta, en función de la relevancia del motivo por el cual se pretenda afectar la libertad de una persona. Siendo el control de identidad uno de los procedimientos que de manera menos intensa afecta la libertad personal en nuestro sistema procesal penal, no cabría exigir para su procedencia fundamentos excesivos más allá de una razonable interpretación de los parámetros del artículo $85 \mathrm{CPP}$. Lo anterior también es aplicable a otras

\footnotetext{
22 Comisión Andina de Juristas, "Comentarios sobre la constitucionalidad del artículo 205 del nuevo Código Procesal Penal (Decreto Legislativo 957)" http://www.cejamericas.org/doc/documentos/caj-opinion-cpp.pdf
} 
garantías, como el derecho al respeto de la intimidad, la igualdad ante la ley, etc.

ii. La interpretación que sostenemos no importa de manera alguna revivir la lógica de la detención por sospecha, tanto es así que se contemplan sanciones a los agentes que actúen de manera irregular, que expresan una señal fuerte en tal sentido. Además, en la medida que la doctrina y la jurisprudencia precisan los fundamentos y límites del control de identidad, decantando estándares que sirvan de referente para la solución de los problemas concretos que se vayan produciendo, se evita precisamente lo que el legislador que suprimió la denominada detención por sospecha consideró más aberrante e impropio de un Estado democrático de derecho: el ejercicio arbitrario de las facultades de las policías.

iii. Lo que sostenemos importa fundamentalmente entender que el control de identidad tiene una razón de ser relevante. No se trata de un mero accidente inserto en el texto del Código Procesal Penal, sino de una herramienta de prevención y persecución penal en sentido amplio, esto es, al servicio de las estrategias de política criminal del Estado, cuyo empleo se confía a la Policía de Investigaciones y a Carabineros de Chile como una facultad autónoma, pero que necesariamente debe considerarse una pieza relevante de un sistema en que los fines básicos no son otros que prevenir la comisión de delitos y esclarecer los ya ocurridos.

\section{Casos fundados e indicio}

Para efectos de una adecuada exposición de nuestros argumentos, en particular del razonamiento consistente en identificar una justificación primordial y amplia, como es la noción de "casos fundados" como fundamento del control de identidad, nos detendremos tanto en tal concepto como en el de "indicio". Nos referiremos separadamente a cada uno de ellos, para efectos de precisar cómo se han entendido, y qué relevancia tiene la determinación de cada uno de ellos para una adecuada aplicación de la normativa sobre control de identidad.

\section{1 "Caso fundado"}

Tal noción ha sido poco estudiada más allá de algunos planteamientos tautológicos, carentes de sustento fáctico y de vinculación a estándares específicos. Así, Sabas Chahuán señala que estamos en presencia de un caso fundado cuando existe "mérito suficiente para controlar la identidad de una persona" 23 , afirmando que el artículo 85 CPP identifica ciertos casos fundados, pero sin embargo "de la sola lectura del texto se desprende que los casos fundados antes

23 Chahuán, Sabas: Manual del Nuevo Procedimiento Penal, Lexis Nexis, Santiago, Segunda Edición, 2002, p. 106. 
Rabi - ¿Qué rol y justificación tiene el control de identidad de una persona...

citados no están establecidos en forma taxativa, por lo que podría extenderse esta figura a otras circunstancias, siempre que estén fundadas". ${ }^{24}$

Pese a que lo anterior nos parece evidente, en las enunciaciones anteriores del artículo $85 \mathrm{CPP}$ no existe gran desarrollo jurisprudencial que pueda respaldar tal planteamiento fundamental. Sin embargo, existen ciertas resoluciones que sostienen tal lógica. Así, el Tribunal Oral en lo Penal de Valparaíso ha resuelto que "el primer eslabón que debe salvar un control de identidad, para entenderlo ajustado a derecho, es estar en presencia de un caso fundado que lo permita, sin embargo la ley no define cuáles son estos casos, limitándose sólo a exponer situaciones explicativas al señalar "tales como" (...)". ${ }^{25}$ En el mismo sentido asevera el juez de garantía de Chillán que "la expresión 'tales como' es una ejemplificación de diferentes situaciones y, en consecuencia, de acuerdo a lo que el fiscal ha señalado (...) sí parece a este tribunal que es un caso fundado en que se pudo pedir la identidad de cualquier persona, por lo que el control de identidad practicado por la policía aparece fundado". ${ }^{26}$

El Fiscal Nacional del Ministerio Público, en el Oficio 544 de 2 de diciembre de 2004, coherente con tal lógica, busca precisar la noción de "casos fundados", señalando que podemos concluir que tal concepto "es el constitutivo de un acontecimiento o suceso, que en virtud a un motivo, razonamiento eficaz o justificado, permite deducir que debe efectuarse un control de identidad, pudiendo ser una de esas razones los indicios del inciso $1^{\circ}$ del artículo 85, descritos como "tales como" u otros semejantes". Tal descripción, sin embargo poco aporta a la hora de buscar identificar tal motivo, razonamiento eficaz o justificado.

Para poder dotar de un contenido útil a este concepto debemos comenzar observando que la adecuada comprensión del texto 85 del CPP, en todas sus formulaciones, supone considerar que la conexión con los fines generales de los procedimientos policiales y en el fondo con la investigación y persecución penal, se produce precisamente a través de la noción general de "casos fundados", por lo mismo éstos serán, aquéllos racionalmente ajustados a tales objetivos respetando los derechos fundamentales de las personas según una adecuada lógica de ponderación.

\footnotetext{
${ }^{24}$ Ibid., p. 106.

${ }^{25}$ RUC 0500272403-2, RIT 25 - 2006. Tribunal Oral en lo Penal de Valparaíso, 24 de marzo de 2006.

${ }^{26}$ J. G. Constitución, 15 enero 2004, B.M.P. N¹8, p. 22, reseñado por Pfeffer Urquiaga, Emilio: Código Procesal Penal Anotado y Concordado, Editorial Jurídica de Chile, Santiago, Segunda Edición, 2006, p. 151. La situación de hecho que motivó el control fue una llamada a Carabineros, alertándolos de que existían dos personas sospechosas merodeando los domicilios del lugar, sin que la persona que efectuó la llamada pudiese aportar más antecedentes.
} 
Ya en el origen de la norma en cuestión, como hemos visto, la formulación original del artículo 260 bis del Código de Procedimiento Penal, "el Senado discutió la forma más adecuada de buscar un equilibrio entre las necesidades derivadas de la conservación de la seguridad pública y el respeto de los derechos de las personas en el contexto de este Código, cuya finalidad es la aplicación de la ley penal, mediante la investigación y el juzgamiento de los hechos delictivos (...)" ${ }^{27}$ Esto es, insinúa que la clave de la instauración de esta institución, y por ende de su interpretación y aplicación, es la ponderación de valores e intereses.

La ubicación del artículo $85 \mathrm{CPP}$, en el párrafo $3^{\circ}$ del Título IV del Libro Primero del CPP titulado "La Policía" y que se refiere a la función de Carabineros de Chile y la Policía de Investigaciones en el procedimiento penal, da cuenta de cuál es la orientación natural de toda la actividad descrita en el párrafo en cuestión: se desprende de la referencia del artículo 79 CPP a los artículos 180 y 181 del mismo cuerpo legal, que esta es colaborar con la investigación de hechos que revisten caracteres de delito dirigida por los fiscales del Ministerio Público. Así es que, una primera aproximación de orden lógico nos lleva a plantear que el control de identidad será justificado en la medida que sea útil para la investigación de delitos.

Es evidente, por otra parte, que no es necesario que se haya producido un delito para que tenga lugar el control de identidad, sino que "en el fondo se trata de actividades de control preventivo (...) para evitar la eventual comisión de hechos delictivos. Siendo facultades de orden policial, en su desarrollo no se podrían encontrar supeditados a las órdenes directivas de los fiscales del Ministerio Público". ${ }^{28}$

En sistemas jurídicos que recogen una tradición similar a la nuestra, como el español, algunos autores han desarrollado con mayor detalle el papel que le cabe a la policía en este sentido. Así, Juan Bustos precisa que la policía "es parte del sistema de control del Estado y, específicamente, del control formal. Más aun es pieza esencial de la intervención del Estado sobre los ciudadanos en relación con un efectivo control: la policía constituye el órgano inmediato de aplicación del control penal y uno de los más importantes del control en general". ${ }^{29}$ Luego desarrolla tal idea diferenciando el papel que a la policía le cabe en la intervención penal del Estado, en la intervención general sancionatoria del poder estatal y precisa las relaciones entre tales cometidos y la libertad de los ciudadanos.

\footnotetext{
27 Pfeffer Urquiaga, Emilio: Código Procesal Penal (notra 26), p. 146.

${ }^{28}$ Carocca, Alex: El Nuevo Sistema Procesal Penal, Lexis Nexis, Santiago, Tercera Edición, 2005, p. 108.

${ }^{29}$ Bustos Ramírez, Juan: Obras Completas, Tomo II Control Social y Otros Cambios, Ediciones Jurídicas de Santiago, Santiago, 2007, p. 302.
} 
Rabi - ¿Qué rol y justificación tiene el control de identidad de una persona...

En nuestro sistema, debemos arrancar de las definiciones establecidas en la carta fundamental, en que se consagra a la Policía de Investigaciones de Chile y a Carabineros de Chile como organismos encargados de cumplir, en principio, la función que les asigna el artículo 101 inciso segundo de la Constitución Política, esto es "dar eficacia al derecho, garantizar el orden público y la seguridad pública interior, en la forma que lo determinen sus respectivas leyes orgánicas. Dependen del Ministerio encargado de la Seguridad Pública". Precisando lo anterior, la ley $\mathrm{N}^{\circ}$ 18.961, Orgánica Constitucional de Carabineros, especifica que el rol fundamental de tal institución es "garantizar y mantener el orden público y la seguridad pública interior en todo el territorio de la República" 30 y que dependerá del Ministerio de Defensa Nacional. Por otra parte, "La misión fundamental de la Policía de Investigaciones de Chile es investigar los delitos de conformidad a las instrucciones que al efecto dicte el Ministerio Público, sin perjuicio de las actuaciones que en virtud de la ley le corresponde realizar sin mediar instrucciones particulares de los fiscales". ${ }^{31}$

Entonces, los funcionarios obligados, en los casos fundados a que nos hemos referido, a practicar el control de identidad, pertenecen a lo que la Constitución genéricamente denomina Fuerzas de Orden y Seguridad Pública, dependientes del Ministerio de Defensa y encargadas, fundamentalmente de mantener el orden y seguridad públicos (prevención) y de investigar delitos (investigación) que son justamente los objetivos fundamentales que determinan la orientación de toda su actividad. ${ }^{32}$ En tal contexto, y en función del cumplimiento de tal misión, no cabe duda de que la policía debe disponer de cierta discrecionalidad que le permita desarrollar su trabajo de manera adecuada a la realidad, discrecionalidad limitada por el respeto de las garantías fundamentales de las personas, pero no por ello menos cierta. Así lo asevera, por ejemplo, Raúl Tavolari, quien plantea el imperativo de "reconocer en forma expresa la necesidad y utilidad de la discrecionalidad policial, no sólo por motivos de carácter fáctico, sino también por el hecho de que sólo a partir

\footnotetext{
30 Art. 1 Ley No 18.961.

31 Art. 4 Ley No 18.322.

32 Siendo así, se ha cuestionado tradicionalmente la dependencia de ellas de un ministerio como el de Defensa Nacional, no vinculado logística ni funcionalmente a los cometidos mencionados. Por tal razón es que una de las reformas importantes que se encuentran pendientes, es la modificación de tal conexión. Existe un proyecto en discusión en el Senado, orientado a traspasar "la dependencia de Carabineros y de la Policía de Investigaciones al Ministerio de Seguridad Pública, con el objeto de lograr una mayor coordinación en la ejecución de las medidas de prevención y control de la delincuencia" (Senado de la República de Chile. Actualidad en www.senado.cl/prontus_senado 16 de junio de 2006). Lo anterior no obsta a que aun hoy, podamos identificar justamente en la prevención y el control delictual, además de la investigación de los hechos punibles, el núcleo duro de la tarea de Carabineros e Investigaciones.
} 
de tal reconocimiento se pueden hacer efectivos los mecanismos de responsabilidad". ${ }^{33}$

El razonamiento que hemos expuesto no es compartido por la totalidad de la doctrina nacional. Así, María Inés Horvitz asevera que "el procedimiento penal sólo puede estar encaminado a la persecución penal de hechos cometidos en el pasado correspondiendo a la policía preventiva la tarea de evitar que se cometan en el futuro nuevos delitos. De allí (que) no se pueda utilizar legítimamente el proceso penal para fines de prevención general, como a nuestro juicio ocurre con la institución del control de identidad (...), por tratarse de un caso prototípico en que se manifiestan las distorsiones de confundir las funciones preventivas y represivas de la policía". ${ }^{34}$ No compartimos tal razonamiento, toda vez que, no obstante su ubicación sistemática, no podemos aseverar que el control de identidad sea una institución puramente de Derecho Procesal, sino de Derecho Público en términos generales, además de entender que resulta manifiesta la intención legislativa de su creación, en términos tales que entendiéndolo de otra manera, no tendría ninguna utilidad práctica ni función relevante. Por otra parte, por el mismo hecho de encontrarse contenido en el código en cuestión, se encuentra sujeto a una serie de garantías generales que aseguran que no se emplee de manera arbitraria ni antijurídica.

La reciente reforma al artículo $85 \mathrm{CPP}$, al establecer que los funcionarios policiales deberán "solicitar la identificación de cualquier persona en los casos fundados, en que, según las circunstancias, estimaren que existen indicios de que ella hubiere cometido o intentado cometer un crimen, simple delito o falta; de que se dispusiere a cometerlo; de que pudiere suministrar informaciones útiles para la indagación de un crimen, simple delito o falta; o en el caso de la persona que se encapuche o emboce para ocultar, dificultar o disimular su identidad..." parece apartamos de la lógica que proponemos, toda vez que parece circunscribir las hipótesis de "casos fundados" que justificarían un control de identidad a la sumatoria especifica de situaciones de hecho que enumera, excluyendo la posibilidad de buscar en los objetivos más generales del trabajo policial el fundamento concreto para proceder al control en cada caso. Sin embargo, afirmamos que la única manera de resguardar la armonía del sistema es sostener aún la lógica que defendemos, al interpretar el artículo $85 \mathrm{CPP}$, sin caer en un fundamentalismo exegético sustentado en un eventual nuevo texto de la disposición citada.

\footnotetext{
33 Tavolari Oliveros, Raúl: Instituciones del Nuevo Proceso Penal, Editorial Jurídica de Chile, Santiago, 2005 , p. 32.

${ }^{34}$ Horvitz, María Inés: "Estado de Derecho y Policía", en Estado de Derecho y Reformas a la Justicia, Universidad de Chile, Heilderberg Center para América Latina, California Western School of Law, Santiago, 2004. p. 72.
} 
Rabi - ¿Qué rol y justificación tiene el control de identidad de una persona...

Tal apreciación ya ha sido recogida por alguna doctrina posterior a la entrada en vigencia de la última reforma a que nos referimos. Así, Rodrigo Cerda y Francisco Hermosilla, considerando el texto actualmente vigente del artículo $85 \mathrm{CPP}$, afirman que el control de identidad "constituye una forma de restricción a la libertad ambulatoria de las personas, consistente en la obligación impuesta a la policía para solicitar su identificación en casos fundados como los indicados ejemplarmente en el precepto que antecede (Art. $85 \mathrm{CPP}) " .35$

\subsubsection{Nuestra propuesta}

Para determinar entonces cuál es el contenido específico de la noción de "casos fundados" consideramos propicio delimitar ciertas cuestiones básicas que permitan un correcto análisis. En ese sentido, afirmamos que la estructura de un "caso fundado" supone:

i. Una situación de hecho particular. Evidentemente sin un antecedente de hecho, no es posible comenzar ningún análisis. Suponemos una persona en un entorno fáctico determinado, compuesto por una mayor o menor cantidad de circunstancias específicas que pueden tener más o menos relevancia.

ii. Debe concurrir, en la situación de hecho en cuestión, una justificación del procedimiento en las necesidades de prevención o persecución penal. Afirmamos que el fundamento final de la institución se encuentra en tales necesidades, no sólo el interés de identificar a una persona, el cual es un objetivo inmediato, pero instrumental. No tendría sentido exigir a una persona que se identifique sin vincular el procedimiento al resto de los múltiples objetivos conexos, tanto generales como específicos, de prevención y/o investigación criminal, entre otros, muy habitualmente, conectar de manera lógica y jurídicamente adecuada, tal procedimiento a la aplicación de medidas que afectan de manera más intensa la libertad de la misma, como la detención, sin que ello importe desconocer las garantías fundamentales del sujeto sometido a control de identidad, de manera antijurídica ni arbitraria.

iii. La justificación anteriormente expuesta debe encontrar en las atribuciones que el artículo $85 \mathrm{CPP}$ entrega a las policías una razonable respuesta a las necesidades específicas de prevención y persecución del caso concreto, en términos tales que el ejercicio de las mismas permita una satisfacción de adecuada intensidad. Además es necesario que los funcionarios de la policía puedan dar cuenta de manera clara y precisa de su razonamiento a la hora de exponer los motivos por los cuales se procedió a controlar la

\footnotetext{
${ }^{35}$ Cerda San Martín, Rodrigo y Hermosilla Iriarte, Francisco: El Código Procesal Penal. Comentarios, Concordancias y Jurisprudencia, Librotecnia, Santiago, Tercera Edición, Abril 2008, p. 84. La referencia al artículo 85 CPP es nuestra.
} 
identidad de una persona. La mera referencia a la experiencia puede transformarse en una excusa para un mal trabajo policial.

Resta entonces por determinar ¿cómo se podrá precisar en cada caso específico si la o las circunstancias de hecho que se esgrimen por las policías como justificación de un control de identidad son o no adecuadas a su naturaleza? La respuesta debería proporcionarla un cuidadoso tratamiento jurisprudencial de las situaciones concretas que examinen los tribunales, basándose en la lógica de estándares ${ }^{36}$, que permita ir delimitando el ámbito de lo que es jurídicamente permitido y lo que no, básicamente procediendo en cada oportunidad a ponderar la relevancia de las garantías fundamentales afectadas y la intensidad de la afectación versus la necesidad o utilidad del procedimiento al servicio de los fines expuestos y la mayor o menor relevancia de las circunstancias de hecho, constitutivas de la "causa justificada" que se esgrima en cada situación puntual. Ello permitiría además definir con claridad en función de qué valores los funcionarios policiales podrán decidir exigirle a una persona que se identifique y cuáles serán las particularidades del procedimiento subsecuente.

\subsubsection{Jurisprudencia de los Estados Unidos}

En la medida que nuestra doctrina y jurisprudencia no han explorado con suficiente profundidad esta cuestión, a saber, cuáles son los límites y ámbitos de acción del trabajo policial en el contexto de investigación y persecución penal, recurriremos a la experiencia comparada, particularmente a la jurisprudencia de los tribunales de Estados Unidos, contexto en el cual se han debatido con latitud diversas cuestiones fundamentales sobre la legitimidad y restricciones del trabajo de los agentes de policía, construyendo una serie de estándares que, si bien están referidos en su mayoría a detenciones en contexto de flagrancia, creemos que revisten gran interés a la hora de determinar los supuestos y alcance del control de identidad y eventual vinculación con circunstancias de flagrancia.

Así por ejemplo, la jurisprudencia norteamericana ha formulado definiciones que permiten entregar soluciones equilibradas y coherentes con la lógica del sistema procesal penal nacional, considerando que la reforma procesal penal, que fundamentalmente importó un cambio de un sistema inquisitivo a uno acusatorio, es plenamente compatible con el modelo

\footnotetext{
${ }^{36}$ Asumimos a este efecto que el artículo $85 \mathrm{CPP}$ no es una norma que contenga, en cuanto a las hipótesis que justifican el control de identidad, planteamientos que deban entenderse como reglas, a saber, prescripciones concretas y específicas establecidas en términos binarios que se aplican derechamente y sin lugar a dudas si es el caso, sino que, más bien, contiene nociones que permiten la construcción de estándares para efectos de su aplicación, esto es, conceptos cuyo contenido es definido por referencia a valores y principios en cada caso específico, construyendo parámetros cuya formulación resultará útil para la solución de casos futuros similares.
} 
Rabi - ¿Qué rol y justificación tiene el control de identidad de una persona...

norteamericano, en el cual se han producido desde antaño discusiones profundas que se han traducido en el establecimiento de estándares jurisprudenciales serios y adecuados a cada problemática.

\section{i. Causa probable como fundamento básico de la detención en los Estados Unidos.}

En el sistema procesal penal de los Estados Unidos, es requisito para proceder a la detención de una persona, que los agentes de la policía estimen que existe una "causa probable" de que ella haya tenido participación en un ilícito. El concepto de causa probable se encuentra consagrado en la cuarta enmienda de la Constitución norteamericana, y ha tenido un notable desarrollo jurisprudencial, toda vez que la concepción original es extremadamente amplia y general, el texto de la misma es el siguiente:

"El derecho de los habitantes de que sus personas, domicilios, papeles y efectos se hallen a salvo de pesquisas y aprehensiones arbitrarias, será inviolable, y no se expedirán al efecto mandamientos que no se apoyen en una causa probable, estén corroborados mediante juramento o protesta y describan con particularidad el lugar que deba ser registrado y las personas o cosas que han de ser detenidas o embargadas".

En la actualidad puede entenderse por tal "todo fundamento razonable para sospechar que una persona ha cometido o está cometiendo un crimen o que en un lugar tiene instrumentalidades específicas relacionadas con un crimen". ${ }^{37}$ Las similitudes con los fundamentos del control de identidad nacional son evidentes, pero, insistimos, en los Estados Unidos, un estándar similar al que en Chile habilita a los agentes de la policía para someter a control de identidad a una persona, en los Estados Unidos, en términos generales y evidentemente subordinados a la legislación de cada estado, habilita a la policía para proceder a la detención del mismo.

\section{ii. Estándar exigido para el registro superficial de vestimentas.}

A partir de ello, creemos que la noción de "Stop and Frisk" que emplea la jurisprudencia de los EE.UU. en particular en Terry $v$. Obio, ${ }^{38}$ fundada en la observación razonable por parte de los agentes de la policía de las circunstancias que los motivan a someter a una persona a "un registro superficial para detectar armas a pesar de que no haya causa probable para el arresto" 39 , nos entrega un criterio orientador que permite establecer un estándar básico sobre la procedencia de tal registro superficial de vestimentas,

\footnotetext{
${ }^{37}$ Muñoz Neira, Orlando: Sistema Penal Acusatorio de Estados Unidos, Legis, Bogotá, 2006, p. 139. 38392 U.S. 1 (1968).

39 Chiesa Aponte, Ernesto: Derecho Procesal Penal de Puerto Rico y Estados Unidos, Forum, Bogotá, 1993, p. 307.
} 
y que posee gran similitud con hipótesis de procedencia "casos fundados" del control de identidad en Chile.

La formulación general del mismo se ha expresado en los siguientes términos: "cuando un policía observa una conducta poco usual que lo lleva razonablemente a concluir, a la luz de su experiencia, que está a punto de producirse una conducta criminal y que las personas sospechosas pudieran estar armadas y ser peligrosas, si en el curso de la investigación de esta conducta el policía se identifica como tal y tras hacer ciertas averiguaciones iniciales permanece o no se disipa su temor por la seguridad propia y de terceros, tiene entonces derecho, para la protección de sí mismo y de terceros en el área, a llevar a cabo un registro, cuidadosamente limitado, de la vestimenta exterior de las personas sospechosas, para descubrir armas que pudieran ser utilizadas para asaltarlo". ${ }^{40}$

Vale la pena destacar de tal fallo que éste refiere una restricción de la libertad de la persona muy leve, que en nuestro sistema es precisamente una de las atribuciones de las policías en el marco del control de identidad, sin facultar a la policía por cierto a exigir al individuo que se identifique, pero pudiendo detenerlo momentáneamente (stop) para efectos del registro superficial (frisk). Lo esencial del razonamiento judicial es que, siendo esta afectación de la libertad de la persona extremadamente tenue, ni siquiera se exige que los agentes de policía deban esgrimir para fundar su procedencia una "causa probable", que es el estándar exigido en los Estados Unidos para que las policías puedan detener a una persona. El tribunal entonces pesa, por una parte, la intensidad de la afectación de derechos, que considera mínima, y por otra, la utilidad que la facultad en cuestión puede proporcionar a la policía, dejando a disposición de la misma esta prerrogativa frente a la constatación de las circunstancias de hecho expuestas, a la luz de la experiencia del agente de la policía.

En nuestro sistema, en general, la jurisprudencia tradicionalmente ha entendido que el mero "olfato policial" es insuficiente a efectos de justificar un control de identidad. ${ }^{41}$ Sin embargo, la referencia a la experiencia policial puede, en nuestro sistema, tener más asidero después de la última reforma del artículo $85 \mathrm{CPP}$, que precisamente incorpora a efectos de la apreciación de los casos fundados que motivan el control de identidad por parte de las policías, aquellos en que según las circunstancias, (los agentes de policia) estimaren constitutivos de los indicios que se detallan. Se trata de una referencia al razonable empleo de la experiencia en el trabajo policial al apreciar las circunstancias de hecho.

Recalcamos también que lo que persigue el tribunal al consagrar el "Stop and Frisk", como el fallo lo señala expresamente es resguardar "la

40 Ibid., traduciendo la sentencia original en lo pertinente. 392 U.S. 1 (1968).

${ }^{41}$ I.C.A. Antofagasta, Rol de ingreso N ${ }^{\circ} 279-07,29$ de diciembre de 2007. 
Rabi - ¿Qué rol y justificación tiene el control de identidad de una persona...

seguridad propia y de terceros" no fomentar la búsqueda de objetos en las vestimentas de las personas mediante el registro superficial que refiere, misma lógica que nos permite afirmar que las atribuciones de la policía en este contexto no se agotan en su finalidad directa. Razonando así, podremos afirmar que el control de identidad en Chile no es un procedimiento única y exclusivamente encaminado a establecer la identidad de una persona, sino que permite además materializar las tareas generales de prevención y persecución penal.

\section{iii. Balancing test, la relevancia de la ponderación.}

Ahora bien, la Corte Suprema de los Estados Unidos ha ido aun más lejos en United States v. Hensley amplía las posibilidades de actuación de las policías, en particular el ejercicio del "Stop and Frisk", como hemos expuesto sin concurrencia de "causa probable", pero basándose el agente policial en un raciocinio serio a la luz de su experiencia sobre los antecedentes de hecho que concurren, incluso en el contexto de una investigación en curso, y con finalidades investigativas argumentando que "en esta zona el interés del gobierno, invocable u oponible a la expectativa legítima de la intimidad, es de menor rango que la situación de Terry. Sin embargo, hay un interés legítimo incuestionable: resolver un crimen y traer al culpable al sistema de justicia criminal. Esto es un interés suficiente para prevalecer en el balance de intereses inherente a Terry". ${ }^{43}$

Continuando con el desarrollo de la idea de proporcionalidad, la Jurisprudencia de los Estados Unidos profundizó el criterio denominado "balancing test", en particular a la hora de ponderar el valor de la prueba obtenida con infracción de garantías en el contexto de lo que en Chile sería un control de identidad ilegal, en cuanto viola garantías fundamentales del imputado. En el caso United States v. Payner, ${ }^{44}$ la Corte Suprema resolvió que "la exclusión de prueba en caso de ilegalidad debe ser sopesada frente al considerable daño que pueda surgir de una aplicación indiscriminada de la regla de la exclusión". Así, la idea que se ha decantado es que corresponde a los tribunales pesar la intensidad del vicio, la afectación de las garantías del individuo y también la conciencia de la infracción por parte del agente (buena o mala fe del policía).

En síntesis, será siempre la ponderación de valores el juicio que debe prevalecer a la hora de calificar la suficiencia de los antecedentes, y la apreciación de los mismos por la policía, en el contexto del registro superficial de vestimentas en el sistema estadounidense, como en el contexto del control de identidad en Chile.

\footnotetext{
42469 U.S. 221 (1985).

${ }^{43}$ Chiesa Aponte, Ernesto: Derecho Procesal... (nota 39), p. 308.

44447 U. S. 727, 736 (1980).
} 
Cierta doctrina en nuestro país ya ha planteado tal lógica de ponderación de valores, pero a efectos de controvertir la legitimidad del procedimiento de control de identidad en sí, en particular con posterioridad a la reforma de la ley 19.789, que, como expusimos anteriormente, amplió las facultades de la policía y el alcance de las hipótesis de procedencia (faltas). Según tal razonamiento, la reforma significó "vulnerar el principio de proporcionalidad en la intervención punitiva del Estado, afectando derechos y garantías ante la supuesta comisión de actos que no representan una afección grave a bienes jurídicos protegidos en un Estado democrático de derecho". ${ }^{45}$ Destacamos y valoramos el propósito de emplear la lógica citada, centrándose inicialmente en ponderar el interés en la persecución penal frente a la relevancia de los derechos fundamentales afectados. Pero creemos que el razonamiento es incompleto, porque si bien es acertado señalar que existe una vulneración cierta a garantías fundamentales frente a sólo una supuesta o posible comisión de delitos, no es menos cierto, que no consideran los autores, a su vez, la intensidad de afectación de garantías, que tratándose del control de identidad es ciertamente mínima. Por ello no compartimos las conclusiones a las que arriban, toda vez que se formula un juicio abstracto asumiendo la preeminencia de ciertos principios sin intentar una auténtica ponderación de valores en el caso concreto.

\section{iv. Relevancia de la buena fe del policía.}

Otra cuestión que se ha discutido en los tribunales superiores de los Estados Unidos, y que en Chile reclama también un pronto debate a la luz sobre todo de la última reforma del artículo $85 \mathrm{CPP}$, que como hemos expuesto se debería traducir en el reconocimiento de la relevancia de la valoración de los agentes de policía de los antecedentes de hecho de un caso fundado, con la incorporación de la referencia expresa a tal apreciación (...según las circunstancias estimaren...) es precisamente la existencia o no de buena fe del policía, relevante, sobre todo si éste comete una equivocación en tal contexto.

La excepción del descubrimiento de buena fe tiene su origen en Adams v. Williams ${ }^{46}$ y se aplica en el sistema norteamericano, por ejemplo, en el caso de que un policía, guiado por la buena fe en su intervención, esto es, actuando con la debida diligencia pero afectado por un error de hecho, realiza un registro ilegal, que en nuestro sistema es una de las facultades del control de identidad, y descubre objetos vinculados a la comisión de un delito. En tal situación no es procedente la declaración de la invalidez del procedimiento, ni

\footnotetext{
45 Morales, Ana María y Galleguillos, Flavio: "Marco de Relaciones entre la Policía y el Ministerio Público en la implementación del Nuevo Procedimiento Penal. Control Jurisdiccional de la Detención”, en Revista de Estudios de la Justicia, Santiago, N², 2003, p. 66.

46407 U. S. 143 (1972).
} 
Rabi - ¿Qué rol y justificación tiene el control de identidad de una persona...

de la prueba obtenida, precisamente porque el mismo fue realizado de buena fe.

Tal criterio ha sido matizado por la Corte de Nueva Jersey, que ha resuelto que "la regla de la buena fe premiaría la incompetencia policial: los policías siempre alegarán que pensaban que era correcto el registro". 47 Evidentemente tal riesgo es cierto y serio, pero creemos que la regla es plenamente aplicable, en la medida que el error de hecho vencible, producto del mero descuido o negligencia es en nuestro sistema procesal y penal incompatible con la buena fe.

\section{v. Relevancia de las circunstancias.}

Hemos afirmado que la nueva redacción del artículo 85 CPP incorpora una referencia que no debería ser considerada intrascendente. El control de identidad se justifica según el texto vigente “...en los casos fundados, en que, según las circunstancias, (los agentes de policía) estimaren...”. Un caso fundado, hemos afirmado, es esencialmente un acontecimiento de hecho; pero para su apreciación las circunstancias particulares del entorno del hecho son también relevantes. Así lo ha resuelto la Corte Suprema norteamericana, considerando que las características de un lugar son importantes para determinar si las circunstancias generan suficientes sospechas como para merecer una investigación, en Adams $v$. Williams, ya citado, y ha insistido más recientemente en tal razonamiento en Illinois $v$. Wardlow. ${ }^{48}$

Los hechos que motivaron este último pronunciamiento, sintéticamente expuestos fueron los siguientes: Wardlow estaba parado en una esquina de un área conocida por ser ámbito frecuente del tráfico de drogas, y huyó cuando vio que se acercaba la policía. Uno de los agentes lo alcanzó y procedió a realizar un registro superficial de sus vestimentas, basado en que, de acuerdo a su experiencia, en ese tipo de vecindarios habitualmente se portan armas. Al encontrar un revólver en su poder, lo detuvo. Wardlow pidió al juez de primera instancia que declarara el revólver inadmisible como prueba porque había sido adquirido durante un procedimiento ilegal, en cuanto la presencia de una persona, de pie, sola, en una "zona de alta criminalidad", no basta para fundar una sospecha razonable y específica de que está realizando una actividad criminal; pero el magistrado rechazó esta solicitud y lo condenó por el delito de porte ilegal de arma de fuego. Tal sentencia fue ratificada por la Corte Suprema en el fallo comentado, sobre la base de la consideración de la relevancia de las circunstancias. Así, un mismo hecho: estar parado en una esquina y huir frente a la presencia policial, puede y debe ser apreciado de

\footnotetext{
${ }^{47}$ Hairabedian, Maximiliano: Novedades sobre la Prueba Judicial, Editorial Mediterránea, 2002, pp. 1419. Citado por Romero Muza, Rubén: Control de identidad... (nota 9), p. 110.

48528 U. S. 119 (2000).
} 
distinta manera dependiendo del resto de las circunstancias que completen el panorama relevante a efectos de su valoración.

\subsection{Indicio}

A diferencia de la noción anterior (caso fundado), la jurisprudencia y la doctrina han desarrollado análisis más detallados sobre el concepto de indicio, en diversos ámbitos del Derecho Procesal. ${ }^{49}$ En el ámbito del control de identidad, aparece bastante acotado en cuanto a su extensión por el mismo texto legal (artículo $85 \mathrm{CPP}$ ) y, a diferencia de la noción de "caso fundado", no cabe sino concluir que los indicios a los que hace referencia el legislador son únicamente aquellos que detalladamente expresa, esto es "de que una persona hubiere cometido o intentado cometer un crimen, simple delito o falta; de que se dispusiere a cometerlo; de que pudiere suministrar informaciones útiles para la indagación de un crimen, simple delito o falta". Otros indicios, en general carecen de relevancia, salvo en cuanto puedan ser constitutivos de una "causa justificada" para proceder al control de identidad en los términos expuestos anteriormente.

\subsubsection{Noción de indicio}

Ahora bien, el concepto de indicio ha recibido un tratamiento más detallado en la doctrina chilena en el contexto del estudio de la teoría de la prueba, en particular al referirse a la prueba indiciaria. También nuestros autores suelen aludir al indicio como uno de los elementos de la estructura lógica de una presunción, identificando el concepto de indicio con el de hecho indicador, o hecho conocido, del cual mediante el empleo de la deducción, o inferencia, se colige el hecho desconocido o deducido. Se trata en el fondo de "ciertos antecedentes o de hechos conocidos que nos permiten establecer un hecho desconocido". ${ }^{50}$ Nos parece que tales ideas básicas son plenamente aplicables al estudio del indicio en el marco del procedimiento penal, y en particular al referirse al rol que le cabe en el control de identidad, por lo que, de manera coherente con lo expuesto, asumiremos por indicio "una circunstancia de hecho conocida, que permite conocer o inferir la existencia de otro no percibido". Estos últimos, los no percibidos, los precisa de manera específica la ley en el texto del artículo 85 CPP.

\subsubsection{Oportunidad de la apreciación del indicio}

Dichas situaciones de hecho conocidas son las que constituyen el objeto de apreciación de las policías y, eventualmente de un pronunciamiento de los

\footnotetext{
${ }^{49} \mathrm{Al}$ efecto interesantes reflexiones conceptuales encontramos en: Arenas Salazar, Jorge: Crítica del Indicio en Materia Penal, Bogotá, Temis, 1988.

${ }^{50}$ Correa Selamé, Jorge: Curso de Derecho Procesal, Tomo III, Ediciones Jurídicas de Santiago, 2006, p. 145.
} 
Rabi - ¿Qué rol y justificación tiene el control de identidad de una persona...

tribunales en los casos que su existencia o relevancia sea controvertida. En tal sentido, asumiendo que los indicios son hechos sujetos a valoración, concordamos con quienes plantean que la apreciación determinante es aquella que se produce en el momento que los agentes de la policía toman contacto con los mismos. Toda aproximación posterior, como puede ser la del fiscal o la del Juez de Garantía, debe asumir que no es razonable juzgar la existencia o consistencia de el o los indicios ni por las consecuencias de la realización del procedimiento $^{51}$ (por ejemplo un hallazgo investigativamente relevante) ni por la apreciación de los mismos efectuada fuera del contexto en cuestión por agentes que no pudieron apreciar la dinámica total de los mismos.

En cuanto a lo primero, esto es la eventual justificación del control de identidad por sus resultados, la doctrina y la jurisprudencia nacional son tajantes: “...no entender que la valoración que debe hacer el tribunal es ex ante al control de identidad, permitiría validar un control de identidad sin estándar por la vía de lo que eventualmente se encuentre al sujeto controlado". ${ }^{52}$ También la jurisprudencia ha refrendado esta lógica temporal sobre la apreciación del indicio. ${ }^{53}$

En cuanto a la relevancia de las circunstancias en que se produce la apreciación original a la que hacemos referencia, es evidente que ella posee ventajas insuperables propias de la proximidad física entre los agentes de la policía y el sujeto controlado en el entorno que motiva el procedimiento: en ninguna otra oportunidad podrán ser apreciados de manera más certera. En tal sentido, una eventual revisión de mérito posterior debe centrarse en determinar, no tanto si los hechos tenían el carácter de indicio en los términos descritos por el artículo $85 \mathrm{CPP}$, sino si era razonable y legítimo que los agentes de policía, de buena fe, así lo apreciaran.

Uno de los pocos aspectos que nos parece positivo de la última modificación del texto en cuestión que hemos comentado es que respalda tal razonamiento, toda vez que agrega, al consagrar la obligación de la policía a proceder al control de identidad, una clara referencia a la importancia de la apreciación policial del hecho que le sirve de sustento al incorporar las palabras "en que, según las circunstancias, estimaren que existen indicios". Tal modificación del texto sólo puede tener sentido sobre la base de la voluntad legislativa de fortalecer la idea de la relevancia del entorno fáctico en que tiene lugar el control de identidad, descartando la posibilidad de que un procedimiento desarrollado de buena fe por las policías pueda ser estimado

\footnotetext{
${ }^{51}$ Ver Romero Muza, Rubén: Control de identidad... (nota 9), p. 76.

52 Blanco, Rafael; Decap, Mauricio; Moreno, Leonardo y Rojas, Hugo: Litigación Estratégica en el Nuevo Proceso Penal, Lexis Nexis, Santiago, 2005, p. 55. En el mismo sentido Romero Muza, Rubén: Control de identidad... (nota 9), p. 74.

${ }^{53}$ RUC 0500505259-0, RIT 17-2006, Tercer Tribunal Oral en lo Penal de Santiago, 22 de febrero de 2006.
} 
ilegítimo sobre la base de una apreciación posterior discrepante de los hechos constitutivos del indicio, formulada después de ellos y fuera del entorno físico de los mismos.

Ello no excluye la posibilidad de que los funcionarios policiales se equivoquen por negligencia inexcusable o actúen de mala fe. Por ello, en tales casos, no podrá entenderse que estemos en presencia de un indicio que reúna las exigencias consagradas en el CPP y, además, deberían hacerse efectivas las sanciones que el artículo ha sugerido al incorporar la referencia al artículo 255 del Código Penal, en caso de verificarse la conducta típica allí prevista de "abusos contra particulares".

Pese a ello, la revisión en sede jurisdiccional de las circunstancias que motivaron el control de identidad no pasa a ser irrelevante "la reforma refuerza claramente y sin lugar a dudas la atribución de las policías de estimar por sí mismas, la existencia de indicios que hacen aconsejable el control de identidad, sin perjuicio de la intervención posterior del tribunal de garantía que está enfocada más bien a evitar arbitrariedades de las policías y no a la revisión de si los indicios que motivaron la acción de las policías existieron o no (...) es decir, si bien los funcionarios tienen facultad para apreciar los indicios, no se ha suprimido el control jurisdiccional del juez de garantía que pudiera eventualmente determinar que existió arbitrariedad en el control de identidad". ${ }^{4}$

\subsubsection{Alcance del indicio}

Por otra parte, según Cisterna Pino, la constatación del indicio de que se trate necesariamente debería llevar al agente policial en cuestión a asumir que la persona cuya identidad se controlará posee algún grado de participación en un hecho delictual cualquiera sea la naturaleza de éste, "si tal indicio no implica atribuirle algún grado de participación en el hecho investigado, no nos imaginamos qué pueda significar, como tampoco nos imaginamos cuál pueda ser la diferencia entre imputado y una persona a la que se le atribuye participación en un hecho punible", 55 afirma el autor citado. No estamos de acuerdo con tal razonamiento, toda vez que según el texto expreso del artículo $85 \mathrm{CPP}$, uno de los indicios que habilita a la policía para proceder a controlar la identidad de una persona es que esta "pudiere suministrar informaciones útiles para la indagación de un crimen, simple delito o falta", lo que no necesariamente importa que ella haya tenido participación culpable en el mismo; basta con que tuviere, o pudiere tener la calidad de testigo, incluso de oídas, o que simplemente existiere un indicio de que ésta sin ni siquiera tener tal calidad pudiese aportar información relevante. El hecho de que tal situación

\footnotetext{
54 Piedrabuena Richard, Guillermo: Ley 20.253 Agenda (nota 15), p. 104.

${ }^{55}$ Cisternas Pino, Adolfo: La detención (nota 4), p. 125.
} 
Rabi - ¿Qué rol y justificación tiene el control de identidad de una persona...

no sea la más habitual no importa asumir la lógica de que siempre un control de identidad conllevará imputar a una persona participación en un ilícito.

Distinta será la situación en la que el indicio en cuestión sea precisamente uno que permita presumir que una persona hubiese cometido algún hecho punible o se dispusiere a cometerlo. Cierta doctrina afirma que en tales casos existe una obligación legal ineludible para la policía consistente en "la exigencia de indicar el delito concreto y específico que constituiría el hecho punible que se estima pesquisado a través del indicio. Es decir, la diligencia debe ser capaz de responder a qué ilícito corresponde el indicio que habilitó su práctica". ${ }^{56}$ En la misma dirección, además, se ha pronunciado alguna jurisprudencia. ${ }^{57}$

Sin embargo creemos que, por una cuestión de orden lógico, parece más razonable afirmar que las policías sólo podrán proceder a un control de identidad habiendo observado un indicio de que una persona pudiere tener participación o se dispusiere a cometer ciertos hechos que pudiesen ser constitutivos de algún ilícito penal, especificando cuál es la categoría o familia del mismo, toda vez que si lo que constatan son sólo indicios, difícilmente podrá depurarse con claridad si estos indicios son, por ejemplo, de un hurto, un robo o receptación; o de un robo en lugar habitado o una violación de morada.

Así lo insinúa la Corte Suprema al señalar que el control de identidad se justifica en "lograr o establecer con certeza la individualización de un sujeto determinado, a fin de obtener posteriormente y con arreglo a derecho y por lo que éste pudiere proporcionar, antecedentes o medios probatorios ya para la indagación de presuntos, pero específicos hechos punibles (...)". ${ }^{58} \mathrm{Tal}$ razonamiento, a diferencia del anterior, pone de manifiesto que lo relevante es la exposición clara de cómo los hechos en cuestión pueden ser constitutivos de delito, sin exigir la asociación a un tipo penal específico y determinado.

Así, por ejemplo, si funcionarios de policía constatan la presencia de una persona escalando por sobre la muralla exterior de un inmueble, parece razonable considerar tal circunstancia como un indicio claro de la comisión de un delito, pero frente a tal constatación primaria, parece desmesurado exigir al agente que pueda precisar si es un indicio de que la persona en cuestión se disponía a cometer violación de morada o robo con fuerza (escalamiento) y menos aun si se trata de la figura del artículo $440 \mathrm{~N}^{\circ} 1$ o de la del $442 \mathrm{~N}^{\circ} 1$ del Código Penal, toda vez que, de no ser un inmueble conocido del agente, este difícilmente podrá tener la certeza si constituye o no morada habitual de una

\footnotetext{
${ }^{56}$ Romero Muza, Rubén: Control de identidad... (nota 9), p. 75.

${ }^{57}$ C.S.J. Rol de ingreso No 3570-06, 20 de septiembre de 2006. RUC 0400136358-7, RIT 850-2004, Juzgado de Garantía de Chillán, 17 de abril 2004.

${ }^{58}$ C.S.J. Rol de ingreso N 3570-06, 20 de septiembre de 2006.
} 
persona. ¿Pero alguien podría seriamente afirmar que ese hecho no es un indicio en los términos del artículo 85 CPP? Por otra parte, ¿sería razonable exigir a los agentes de policía, en el ejercicio de sus facultades autónomas, la profundidad de conocimientos jurídicos necesaria para hacer las precisiones jurídicas a veces sutiles, que suponen los ejemplos expuestos?

En la práctica lo relevante es que el personal policial que efectúa un control de identidad tenga cabal conocimiento de cuál es la utilidad y limitaciones que posee tal institución como herramienta de prevención e investigación delictual, en términos tales que al emplearlo, lo haga con pleno conocimiento de su naturaleza y procedencia, lo que le permitirá a su vez exponer con detalle cuáles fueron las circunstancias de hecho que motivaron el control, para efectos de la revisión de las mismas ante el Juez de Garantía cuando sea procedente, y que no se emplee como una figura tendiente a justificar procedimientos policiales frente a circunstancias difusas, o basados en meras suposiciones o prejuicios infundados.

\section{Control de identidad y detención}

A continuación, nos referiremos a una de las cuestiones más controvertidas del estudio del control de identidad, esto es, la relación que puede existir entre éste y la detención. La relevancia de esta cuestión es manifiesta, toda vez que "es muy excepcional (...) que sin que se haya practicado la detención, se discuta el tema de la legalidad del control de identidad en alguna sede jurisdiccional". ${ }^{59}$

La doctrina y la jurisprudencia nacional no han explorado con suficiente profundidad una cuestión que consideramos determinante para el análisis de tal relación: cuáles son los límites y ámbitos de acción del trabajo policial en el contexto de investigación y persecución penal, que según hemos expuesto, son los parámetros que justifican el control de identidad, en cuanto son el referente fundamental de la noción de "casos fundados".

En tal sentido, podemos identificar dos líneas de argumentación opuestas que se han empleado a efectos de afirmar, por una parte, que el control de identidad únicamente es un instrumento tendiente a obtener que un individuo se identifique, y cualquier otro propósito investigativo en el marco del procedimiento en cuestión no podrá expresarse en la medida que la persona se identifique convenientemente, esto es: el control de identidad termina con la acreditación de la misma. Así, Horvitz y López sostienen que "en el contexto cultural de nuestro país, en que el porte de documentos de identificación y, en particular, de la cédula nacional de identidad es una costumbre arraigada, pareciera que, de respetarse el control de identidad previsto por la ley, éste debiera llevar muy rara vez a la conducción de una

\footnotetext{
${ }^{59}$ Piedrabuena Richard, Guillermo: Ley 20.253 Agenda (nota 15), p. 105.
} 
Rabi - ¿Qué rol y justificación tiene el control de identidad de una persona...

persona a la unidad policial". ${ }^{60}$ También la jurisprudencia previa a la última reforma del texto del artículo 85 CPP sostenía tal planteamiento. ${ }^{61}$

Una segunda corriente argumentativa conforme a la cual el control de identidad, pese a ser en nuestro sistema procesal penal una institución distinta de la detención, puede estar estrechamente conectado con la detención, sea esta última producto de una orden judicial o de una situación de flagrancia que ocurra en el contexto del control de identidad, con arreglo a lo dispuesto en el artículo 130 del CPP.

Como cuestión preliminar, debemos hacer presente que parte de la doctrina nacional ni siquiera considera que exista una diferencia esencial entre control de identidad y detención. Así, según Cisterna Pino, el control de identidad "puede llegar a constituir una verdadera detención, aunque la ley no la denomine así". ${ }^{62}$ Más radical aun es Cristián Arias, quien argumenta observando que, entre nosotros, el control de identidad, en particular cuando importa un traslado a la unidad policial, es “...una auténtica detención (...) de allí que entre nosotros tenga cabida la idea de adoptar un concepto amplio de detención, comprensivo de toda privación de libertad ambulatoria que no sea prisión preventiva o ejecución de pena". ${ }^{3}$

Asumiremos como cierta la visión mayoritaria, según la cual son instituciones diversas y claramente distinguibles una de otra. Así lo postula, por ejemplo, Guillermo Piedrabuena, quien sostiene que "el mero control de identidad no conlleva detención de la persona, salvo que sea sorprendido en una hipótesis de flagrancia o tenga órdenes de detención pendientes o se niegue a identificarse o proporcione una identidad falsa". ${ }^{64}$

\subsection{Primera línea argumental: incompatibilidad absoluta entre control de identidad y detención}

La primera línea argumental que hemos referido reclama una estricta autonomía e incompatibilidad entre el control de identidad y la detención. En particular, se plantea la incompatibilidad entre el procedimiento descrito en el artículo 85 CPP. y la detención en virtud de una circunstancia de flagrancia que

\footnotetext{
${ }^{60}$ Horvitz, María Inés y López, Julián: Derecho Procesal Penal Chileno, Tomo I, Editorial Jurídica de Chile, Santiago, 2002, p. 380.

${ }^{61}$ RUC 0400301730-9, RIT 1081-04, 20 de agosto de 2004. En particular el Juez de Garantía de San Fernando afirma en estos autos que cuando "los imputados exhibieron su cédula de identidad a los funcionarios policiales que se las pidieron eso consta en el parte, el control de identidad debió haber llegado hasta ahí".

${ }^{62}$ Cerda San Martín, Rodrigo y Hermosilla Iriarte, Francisco: El Código Procesal Penal... (nota 35), p. 84.

63 Arias, Cristián. "El Control Jurisdiccional de la Detención", en Revista de Estudios de la Justicia, Santiago, N6, 2005, p. 231.

${ }^{64}$ Piedrabuena Richard, Guillermo: Ley 20.253 Agenda (nota 15), p. 105.
} 
pueda aparecer en tal contexto. Los argumentos más relevantes en ese sentido, son los siguientes.

4.1.1 La institución que vino a remplazar la detención "por sospecha" no solamente es diferente a ésta, sino independiente e incompatible con las finalidades de cualquier tipo de detención por flagrancia, por lo que difícilmente pueden tener lugar en un mismo contexto; "la utilización de las facultades que otorga el control de identidad, muchas veces en forma desnaturalizada o abusiva, determina que ambas instituciones se enlacen como eslabones sucesivos de un mismo procedimiento, culminando en detención por flagrancia sin distinguir los estándares formales de actuación e invasividad de derechos que cada institución supone". ${ }^{65}$

El origen de este argumento es precisamente la diversa finalidad de ambas instituciones, pese a que, como ya señalamos, una parte minoritaria de la doctrina postula que el control de identidad no es sino una forma de detención, relativamente pacífico, en nuestra doctrina y jurisprudencia que estos procedimientos son esencialmente distintos y persiguen objetivos distintos. Mientras la detención por flagrancia es una forma de afectación de la libertad personal cuya finalidad está definida en la Constitución, esto es, que el detenido "sea puesto a disposición del juez competente dentro de las veinticuatro horas siguientes" (Art. $19 \mathrm{~N}^{\circ} 7$ de la Constitución), eventualmente en la audiencia que tenga lugar ante el juez competente, el juez de garantía, podrán discutirse medidas cautelares de mayor intensidad; sin embargo, la finalidad de la detención no puede ser otra que conducir al imputado ante la magistratura competente a efecto de revisar en primer lugar la legalidad de la detención y acto seguido permitir al Ministerio Público ejercer sus facultades y dar lugar al debate jurídico que sea pertinente según el caso. El control de identidad, a diferencia de la detención, posee “...una finalidad específica, cual es obtener la identidad de una persona, que a partir del indicio que motivó la diligencia se configura como imputado o testigo". ${ }^{66}$

Siendo entonces ambas instituciones, distintas, no cabe, según esta argumentación, afirmar la compatibilidad de ambos procedimientos en un mismo ámbito fáctico.

4.1.2 Se trata de un argumento de carácter lógico vinculado al anterior, en la medida en que, insistiendo en la incompatibilidad de control de identidad y la detención por flagrancia, quienes lo sustentan afirman que de aparecer antecedentes que den cuenta de la necesidad de la detención en el contexto de un control de identidad debería recurrirse a solicitar orden judicial al efecto, de acuerdo con lo dispuesto en los artículos 125 y 127 del CPP. En efecto, en materia de detención "la regla general es la detención por orden judicial o de

\footnotetext{
${ }^{65}$ Romero Muza, Rubén: Control de identidad... (nota 9), p. 83.

${ }^{66}$ Ibid., p. 65.
} 
Rabi - ¿Qué rol y justificación tiene el control de identidad de una persona...

funcionario legalmente autorizado para dictarla, y por su parte. La excepción es que la policía sin orden previa (art. 83 letra b) y art. 129 CPP) o cualquier persona (art. $130 \mathrm{CPP}$ ) puedan detener a alguien a quien sorprendieron en delito flagrante". ${ }^{67}$

Algunos fallos han respaldado enérgicamente este argumento, así, se ha afirmado que "si durante el tiempo que la policía retiene a una persona para controlar su identidad, el Ministerio Público reúne antecedentes que estima suficientes para justificar la existencia de un delito y la participación del sujeto controlado, procede entonces que solicite la correspondiente orden a la autoridad competente, el juez". ${ }^{68}$

4.1.3 Por tratarse de un procedimiento que, aunque de manera leve, afecta los derechos de la persona en cuestión, el ámbito de aplicación de la norma debe interpretarse de manera restrictiva, lo que impide la conexión de control de identidad con detención por flagrancia. Romero Muza es categórico en ese sentido: “...al tratarse de una institución excepcional cuyo tenor autoriza la restricción de la libertad o de otros derechos de las personas debe interpretarse restrictivamente al momento de aplicarse, de conformidad al art. $5^{\circ}$ inciso $2^{\circ}$ del CPP". Tal argumento eso sí, no resiste el análisis del texto actualmente vigente del artículo 85 del C.P.P.

\subsection{Segunda línea argumental: compatibilidad entre control de identidad y detención}

La línea de argumentación contrapuesta, que compartimos, asume que existe compatibilidad entre la detención por flagrancia y el control de identidad. Se afirma que la vinculación entre control de identidad y flagrancia se legitima:

4.2.1 En primer lugar en razón del nuevo texto del artículo 85, que así lo admite expresamente. De este modo, el inciso segundo de la disposición citada prescribe: "La policía procederá a la detención, sin necesidad de orden judicial y en conformidad a lo dispuesto en el artículo 129, de quienes se sorprenda, a propósito del registro, en alguna de las hipótesis del artículo 130, así como de quienes al momento del cotejo registren orden de detención pendiente". Disponiendo de tal herramienta legal las policías, lo más razonable y coherente con la lógica del sistema es que la empleen de manera estratégica adecuada a su planificación y finalidades.

\footnotetext{
${ }^{67}$ Ibid., p. 85.

68 RUC 0200019412-6, RIT 754-02, 14 de febrero de 2002.

${ }^{69}$ Romero Muza, Rubén: Control de identidad... (nota 9), p. 86. Además el autor hace referencia al Instructivo General No 19 de la Fiscalía Nacional, dirigido a las Policías, en el cual este afirma que "...en caso de duda los funcionarios deben abstenerse de detener, poniendo los antecedentes a disposición del fiscal, para que este resuelva lo que estime pertinente”.
} 
REJ - Revista de Estudios de la Justicia - No 13 - Año 2010

4.2.2. Estimamos que tal planteamiento tiene no sólo un sustento estrictamente legal, sino que además se justifica a la luz de los valores del sistema, asumiendo que el control de identidad ha sido concebido como un mecanismo tendiente a conciliar, por una parte, la eficiencia de los procedimientos policiales orientados, en primer lugar y antes que todo, a sus propios fines generales y específicos (aclarar ilícitos, determinar sus partícipes, etc.) con una adecuada manera de entender las garantías fundamentales, por otra, que necesariamente importa el ejercicio de una razonable ponderación de las mismas de cara a los fines señalados. De este modo, lo que se busca no es simplemente esclarecer la cuestión concreta sobre cuál sea la identidad de una persona, sino hacerlo en el contexto de un procedimiento policial encaminado a los fines señalados, orientado por criterios de eficiencia y limitado por el adecuado respeto de los derechos fundamentales, esto es, en definitiva, no identificar por identificar, sino hacerlo para efectos de desarrollar persecución penal.

4.2.3 Consideramos que la independencia conceptual de dos instituciones, como el control de identidad de detención y la flagrancia no importa desde una perspectiva lógica descartar las posibilidades de vinculación entre las mismas, sobre todo cuando las estrategias de persecución penal así lo requieren.

En tal sentido, nos parece equivocado el argumento antes expuesto sobre el alcance de la exigencia de interpretar restrictivamente el artículo 85 $\mathrm{CPP}$, puesto que, en rigor, tal forma de hermenéutica supone que el operador jurídico se ciña al texto de la norma, limitándose a aplicarla a los supuestos estrictamente comprendidos en ella, toda vez que, incluso si aplicamos una interpretación de tal modalidad, no aparece, ni en ninguna redacción anterior del artículo $85 \mathrm{CPP}$ ha aparecido, incompatibilidad alguna que impida la detención por flagrancia en el contexto de un control de identidad, porque la disposición examinada nada de eso dice, y muy por el contrario, como hemos expuesto antes, la última reforma incorpora una mención explícita en sentido contrario.

El argumento tampoco tiene sentido si se postula una interpretación restrictiva de los artículos 129 y 130 del CPP, en función del artículo 85 del mismo cuerpo legal, toda vez que en ninguno de ellos se plantea una exclusión expresa de la detención por flagrancia respecto de la persona que se encuentra sometida a control de identidad. Si el legislador no lo hace, ¿qué argumento lógico nos podría llevar a plantear tal exclusión?

Como anticipábamos, la base de análisis que nos permitirá determinar el alcance de ambas instituciones consiste en especificar los límites y ámbitos de acción del trabajo policial en el contexto de investigación y persecución penal, todo ello considerando el sistema de garantías fundamentales propio de nuestro estado de derecho. 
Rabi - ¿Qué rol y justificación tiene el control de identidad de una persona...

Ya señalamos anteriormente que el trabajo policial debe estar orientado fundamentalmente en nuestro país a la prevención y el control delictual, además de la investigación de los hechos punibles; pero determinar las expresiones concretas de tales objetivos genéricos que serán toleradas pese a que limiten o restrinjan las garantías fundamentales, es tarea de la jurisprudencia, a través del empleo razonable de la lógica de ponderación y establecimiento de estándares.

4.2.4 También existen argumentos fundados en la historia fidedigna del establecimiento de la ley 20.253, en particular de la discusión parlamentaria, sobre el cotejo de órdenes de detención. La discusión de fondo en tal sentido fue si la persona, una vez que se identificaba satisfactoriamente, podía ser trasladada o no a la unidad policial, para efectos de verificar la existencia de órdenes de detención pendientes o tal procedimiento debía necesariamente llevarse a cabo en el lugar en que se origina el control de identidad. Tal asunto no resultó del todo claro pese a que algunos parlamentarios asumieron que sí era posible (Edmundo Eluchans), al parecer la mayoría se inclina por la negativa. Pero lo que se asume a todo evento como indiscutible es que el procedimiento del artículo $85 \mathrm{CPP}$ no termina necesariamente con la identificación de la persona sujeta a control. ${ }^{70}$

\section{Conclusiones}

Para finalizar expondremos las conclusiones de todo lo antes expuesto, en particular:

1. El control de identidad no es un mecanismo que tiene por fin único y último la identificación de personas; tal obligación de las policías de exigir la identificación de las personas sólo tiene un genuino sentido entendida como una pieza de un sistema. De hecho, si no se entendiera así, la afectación de garantías, cualquiera sea su intensidad, sería siempre de dudosa juridicidad, toda vez que se sustentaría en una finalidad vana e irrelevante, y al ponderar los valores en juego, no podría prevalecer el "interés en determinar la identidad de una persona" como valor intrínseco, enfrentado a la libertad, intimidad u otros derechos fundamentales del individuo. Por el contrario, la justificación del control de identidad, considerando la lógica del sistema, el rol que la Constitución y las leyes le encomiendan a las policías en Chile, y la naturaleza de las atribuciones que en virtud del control de identidad los funcionarios

\footnotetext{
70 “El Diputado Eluchans propuso y entendió que la Comisión así lo aceptaba, que la persona controlada debía ser llevada al cuartel policial, aunque se identificara satisfactoriamente, para los efectos del cotejo de posibles órdenes de detención, asunto que no quedó aclarado suficientemente (...) estimamos que si la identificación es exitosa, el cotejo de las órdenes de detención debe hacerse en el mismo lugar del control de identidad" (Piedrabuena Richard, Guillermo: Ley 20.253 Agenda (nota 15), p. 108).
} 
policiales pueden ejercer, es materializar fines de prevención y persecución penal.

2. Siendo así, es evidente que debe ser empleado con pleno respeto de los derechos y garantías de las personas, y acotado por las causales establecidas en el artículo 85 CPP interpretadas a la luz de su finalidad sistemática y mediante una adecuada ponderación de valores.

En tal sentido resulta adecuado que en cada caso particular en que los tribunales deban revisar la actuación de los agentes de policía el razonamiento judicial comience por identificar los fines concretos que en el caso específico tuvieron en consideración a la hora de efectuar el control de identidad y el grado de certidumbre que los agentes poseían respecto de los antecedentes de hecho y sus circunstancias: en tal sentido será más valioso como antecedente y más sólido como motivo (1) la prevención o persecución de un delito relativamente más grave y (2) si existe mayor certeza sobre su comisión, y si es el caso (hemos afirmado que no es necesario que a una persona se le impute participación culpable en un delito para proceder al control de identidad), de la participación de la persona sujeta a control de identidad en el mismo.

El mismo ejercicio debería hacerse al ponderar las garantías afectadas considerando (1) qué derechos específicos se afectaron y (2) con qué intensidad se produjo la afectación. La mera consulta de la identidad satisfecha por la exhibición de la cédula nacional de identidad, por ejemplo, importa una muy tenue afectación de la libertad ambulatoria y la garantía de la protección de la intimidad. Si a ello adicionamos en la práctica un registro superficial de vestimentas, la afectación será menos tenue y será definitivamente más intensa si se requiere el traslado a la unidad policial de la persona sometida a control de identidad.

3. Lo anterior nos permite concluir que existe una estrecha relación entre el control de identidad y otras restricciones de la libertad de las personas de mayor intensidad como la detención, toda vez que la función que ambas cumplen en el sistema es similar difiriendo en cuanto a la intensidad de la afectación de la libertad personal y la amplitud de las hipótesis de procedencia, pero no en los fines al servicio de los cuales están establecidas. Por lo demás, en ninguna disposición de la Constitución o del CPP se ha planteado la incompatibilidad de ambas, ni existe ningún principio, valor o razonamiento convincente que nos pueda llevar a tal conclusión y, a mayor abundamiento, tras un interesante debate generado en el Congreso en el marco de la reciente modificación al texto del artículo $85 \mathrm{CPP}$, sobre la eventual necesidad de nuevos indicios para proceder al registro de vestimentas, equipaje o vehículo una vez que se ha sometido a una persona a control de identidad, hubo 
Rabi - ¿Qué rol y justificación tiene el control de identidad de una persona...

consenso en que ello no era necesario y, en definitiva, el nuevo inciso segundo del artículo $85 \mathrm{CPP}^{71}$ es expresión de tal lógica. ${ }^{72}$

4. La reciente modificación del texto del artículo 85 CPP no es del todo feliz en cuanto parece consagrar una justificación del control de identidad, circunscrita a específicas autorizaciones legales, expresadas en lógica de reglas y no de estándares. Sin embargo, afirmamos que tal lectura es sólo aparente, nos parece que la interpretación que proponemos, esto es, identificar la justificación del control de identidad en las necesidades de prevención y persecución criminal en términos amplios, es la única que permite dotar de sentido a la norma que examinamos. Por otra parte, nos parece que la reforma contiene aspectos positivos en cuanto valora la función de la experiencia policial en la apreciación de las circunstancias de hecho, "casos fundados" que motiven al agente a proceder al control de identidad. No nos parece que ello importe un riesgo desmesurado de arbitrariedad en la actuación de las policías, dado el régimen de responsabilidad administrativo y penal al que están sujetos en su actuación. Pero, antes que eso, el gran límite a la arbitrariedad policial aún podemos encontrarlo en el rol de control de la autoridad jurisdiccional, en cada etapa del procedimiento.

En efecto, no sólo la existencia de las sanciones nos debería llevar a tal conclusión. Nuestro sistema constitucional se basa en la responsabilidad de todos los órganos que forman parte de la administración del Estado; ya en los artículos 6 y 7 de la Constitución se consagran tales principios, comprendiendo a las policías en el alcance de la exigencia de someter su acción a la Constitución y a las normas dictadas conforme a ella y garantizar el orden institucional de la República. Todo poder jurídico en el marco del derecho público nacional conlleva como consecuencia inevitable responsabilidad en su ejercicio y la obligación de orientarlo a los fines sistemáticos para los que fue previsto. Los órganos jurisdiccionales son, por antonomasia, los primeros llamados a velar por la plena vigencia de tales imperativos constitucionales.

Evidentemente, creemos que el estudio del control de identidad no se agota con las reflexiones expuestas, y sobre todo esperamos con optimismo la reflexión profunda de los magistrados al resolver los conflictos que tengan lugar a propósito de la nueva redacción del artículo $85 \mathrm{CPP}$, sin olvidar las cuestiones que se encuentran pendientes, que permita no tener que recurrir a sucesivas modificaciones del texto legal que atentan contra la seguridad

\footnotetext{
71 Art. 85 inciso segundo: "Durante este procedimiento, sin necesidad de nuevos indicios, la policía podrá proceder al registro de las vestimentas, equipaje o vehículo de la persona cuya identidad se controla, y cotejar la existencia de las órdenes de detención que pudieren afectarle. La policía procederá a la detención, sin necesidad de orden judicial y en conformidad a lo dispuesto en el artículo 129, de quienes se sorprenda, a propósito del registro, en alguna de las hipótesis del artículo 130, así como de quienes al momento del cotejo registren orden de detención pendiente"

72 Piedrabuena Richard, Guillermo: Ley 20.253 Agenda (nota 15), pp. 97-103.
} 
jurídica y la estabilidad institucional, para clarificar cuestiones que a través de una dinámica determinación de estándares de aplicación pueden encontrar una respuesta más acertada, realista y coherente con la lógica general del sistema.

En tal sentido creemos también que será responsabilidad del resto de los intervinientes en el proceso penal permitir que se genere tal debate, toda vez que si bien las posibilidades de negociación de aquéllos han generado efectos positivos ciertos en la implementación y funcionamiento eficiente de la reforma procesal penal, muchas veces son un obstáculo a que se discutan cuestiones trascendentes sobre el alcance de instituciones relevantes, por ejemplo: acuerdos en el contexto de audiencias de control de detención en que, a cambio de no discutir la legalidad de una detención basada en un control de identidad dudoso, los fiscales solicitan medidas cautelares de menor intensidad que las que sería razonable y prudente requerir.

Todos estos desafíos son los propios de un sistema que se encuentra en etapa de maduración y que, si bien ha sido relativamente exitoso, denota aún falta de determinación de los intervinientes en tareas pendientes como las que hemos expuesto. 
Rabi - ¿Qué rol y justificación tiene el control de identidad de una persona...

\section{BIBLIOGRAFÍA}

* ARENAS Salazar, Jorge: Crítica del Indicio en Materia Penal, Temis, Bogotá, 1988.

* ARIAS Vicencio, Cristián: "El Control Jurisdiccional de la Detención”, en Revista de Estudios de la Justicia, Santiago, Nº, 2005.

* BLANCO, Rafael; DECAP, Mauricio; MORENO, Leonardo y ROJAS, Hugo: Litigación Estratégica en el Nuevo Proceso Penal, Lexis Nexis, Santiago, 2005.

* BUSTOS Ramírez, Juan: Obras Completas, Tomo II Control Social y Otros Cambios, Ediciones Jurídicas de Santiago, Santiago, 2007.

* CAROCCA, Alex: El Nuevo Sistema Procesal Penal, Lexis Nexis, Santiago, Tercera Edición, 2005.

* CERDA San Martín, Rodrigo y HERMOSILlA Iriarte, Francisco: El Código Procesal Penal. Comentarios, Concordancias y Jurisprudencia, Librotecnia, Santiago, Tercera Edición, Abril 2008.

* CHAhUÁn, Sabas: Manual del Nuevo Procedimiento Penal, Lexis Nexis, Santiago, Segunda Edición, 2002.

* CHIESA Aponte, Ernesto: Derecho Procesal Penal de Puerto Rico y Estados Unidos, Forum, Bogotá, 1993.

* CISTERNAS Pino, Adolfo: La Detención por Flagrancia, Librotecnia, Santiago, 2005.

* CORREA Selamé, Jorge: Curso de Derecho Procesal Tomo III, Ediciones Jurídicas de Santiago, Santiago, 2006.

* DuCE, Mauricio y RIEGO, Cristián: Proceso Penal, Editorial Jurídica de Chile, Santiago, 2007.

* GONZÁleZ, Felipe y RIEGO, Cristián: "Las Garantías de la Detención en Chile" en Proceso Penal y Derechos Fundamentales, Corporación Nacional de Reparación y Reconciliación, Santiago, 1994.

* Hairabedian, Maximiliano: Novedades sobre la Prueba Judicial, Editorial Mediterránea, Córdoba, 2002.

* HORVITZ, María Inés y LÓPEZ, Julián: Derecho Procesal Penal Chileno, Tomo I, Editorial Jurídica de Chile, Santiago, 2002.

* HORVITZ, María Inés: "Estado de Derecho y Policía", en Estado de Derecho y Reformas a la Justicia, Universidad de Chile, Heilderberg Center para América Latina, California Western School of Law, Santiago, 2004.

* MORAles, Ana María y GAlleguillos, Flavio: "Marco de Relaciones entre la Policía y el Ministerio Público en la implementación del Nuevo Procedimiento Penal" Control Jurisdiccional de la Detención”, en Revista de Estudios de la Justicia, Santiago, N², 2003.

* MUÑOZ Neira, Orlando: Sistema Penal Acusatorio de Estados Unidos, Legis, Bogotá, 2006.

* PFEFFER Urquiaga, Emilio: Código Procesal Penal Anotado y Concordado, Editorial Jurídica de Chile, Santiago, Segunda Edición, 2006.

* PIEDRABUENA Richard, Guillermo: Ley 20.253 Agenda Corta Antidelincuencia, Legis, Santiago, 2008.

* Romero Muza, Rubén: Control de Identidad y Detención, Librotecnia, Santiago, Segunda Edición, 2007.

* TAVOLARI Oliveros, Raúl: Instituciones del Nuevo Proceso Penal, Editorial Jurídica de Chile, Santiago, 2005. 
REJ - Revista de Estudios de la Justicia - No 13 - Año 2010

\section{DOCUMENTOS}

* Comisión Andina de Juristas, "Comentarios sobre la constitucionalidad del artículo 205 del nuevo Código Procesal Penal (Decreto Legislativo 957)" http://www.cejamericas.org/doc/documentos/caj-opinion-cpp.pdf

* Documento de la Comisión Nombrada para Revisar y Evaluar la Marcha y Funcionamiento del Nuevo Sistema de Enjuiciamiento Criminal, Diciembre de 2003.

* Informe Comisión de Evaluación de la Reforma Procesal, Octubre 2001.

* Senado de la República de Chile. Actualidad en www.senado.cl/prontus_senado 16 de junio de 2006. 